Title: Volant Fossil Vertebrates: Potential for Bioinspired Flight Technology

Authors: Elizabeth Martin-Silverstone*, Michael B Habib, David W E Hone

Authors' addresses

*Elizabeth Martin-Silverstone

School of Earth Sciences, University of Bristol, Life Sciences Building, 24 Tyndall Avenue, Bristol, BS8 1TQ, United Kingdom

Liz.martin@bristol.ac.uk

Twitter: @gimpasaura

Michael B Habib

Dinosaur Institute, Natural History Museum of Los Angeles County, 900 W Exposition Blvd, Los Angeles, CA 90007

David W E Hone

School of Biological and Chemical Sciences, Queen Mary University of London, Mile End Road, London, E1 4NS, United Kingdom

Keywords: flight, evolution, bioinspiration, biomechanics, biomimetics, fossils 


\title{
VOLANT FOSSIL VERTEBRATES: POTENTIAL FOR BIOINSPIRED FLIGHT TECHNOLOGY
}

\begin{abstract}
Animal flight is ecologically important and has a long evolutionary history. It has evolved independently in many distantly related clades of animals. Powered flight has evolved only three times in vertebrates, making it evolutionarily rare. Major recent fossil discoveries have provided key data on fossil flying vertebrates and critical insights regarding the evolution and different arrangements of animal flight surfaces. Combined with new methodologies, these discoveries have paved the way for potentially expanding biomimetic and biologically inspired designs to incorporate lessons from fossil taxa. Here, we review the latest knowledge and literature regarding flight performance in fossil vertebrates. We then synthesize key elements to provide an overview of those cases where fossil flyers might provide new insights for applied sciences.
\end{abstract}

\section{Powered flight in vertebrates}

The evolution of powered flight (see Glossary) has rarely occured in the history of vertebrate life. While there are numerous clades with members that engage in unpowered flight, powered flight has only evolved three times within vertebrate lineages, in the birds (Aves), bats (Chiroptera) and extinct pterosaurs (Pterosauria), and once in invertebrates (Insecta). Despite the rarity of powered flight as an evolved behaviour, powered flyers are common both in terms of numbers of species and individuals. Birds are the most speciose group of living terrestrial vertebrates [1] and bats are the second-most diverse clade of mammals [2]. Making an accurate species count of pterosaurs is difficult, but we can be confident that they were an important part of Mesozoic ecosystems for over 160 million years [3]. Recent reviews on birds [4], bats [5], and insects [6] have focused on studies of aerodynamics, biomechanics, and anatomical aspects of 
flight in these animals, derived from the high quality and quantity of data available from extant animals, something that is more difficult and rare in extinct taxa (e.g. pterosaurs, [7]).

The rarity of powered flight may be a result of the relatively strict requirements to generate sufficient power to overcome drag and resisting the large resultant forces (without excessive weight), while also controlling and directing movement. These physical demands require skeletons with high stiffness:weight ratios and sophisticated control surfaces [8]. Unpowered flight is more common, being known from numerous extant and extinct lineages, though it has some similar requirements [9] (Box 1). Despite constraints, each group of flying vertebrates has a fundamentally different set of anatomical "solutions" to common challenges of aerial locomotion (Fig 1).

Major fossil discoveries in recent years have provided key data on fossil flying animals. The Daohugou localities in China have produced the earliest known gliding mammal (Volaticotherium [10]) (Box 2), the oldest possible flying dinosaur (Anchiornis [11]) and new information on the structure of pterosaur wings [12]. New techniques are available to extract the available structural data and manipulate it with information from UV light [13], and surface and penetrative scanning $[14,15]$. Therefore, understanding flight in fossil forms is now considerably enhanced compared to previous years, and is set to advance further and at an increasing rate.

These new data have greatly expanded understanding of how flying animals have solved major flight challenges, including novel evolutionary solutions not seen in living species. Fundamental aspects of flight, including take-off [16,17], landing [18], the shape [19], structure [20,21] and position of control surfaces [22], glide angles [23,24], flight strokes [25], flying style [26], and active control of wings [12] are being increasingly explored in living and fossil taxa. Unique fossil-only bauplans have also been described, such as the non-avialan dinosaurs $Y i$ qi and Ambopteryx [27,28]. 
These discoveries have paved the way for the possibility of expanding biomimetic and biologically inspired design approaches to incorporate lessons from fossil taxa. A robust understanding of the origin of flight and the evolution of morphologies related to flight performance provides critical context for the constraints and optimization of biological traits that can inspire mechanical design.

\section{Wing structure and materials}

\section{Feathers}

New fossils combined with novel analyses have revealed important information on the size [29], arrangement [30], and strength [20] of the flight feathers in early birds and non-avialan dinosaurs. Integrated with new assessments of the wing positions [29], these data shed new light on the transition from gliding to powered flight. The evolution of flight-related characters, including feathers, appears to have followed a mosaic pattern, with many of the key morphologies seen in flight feathers appearing in non-flying avian relatives [31-33].

Of the key features in feathers related to sustained flight, feather vane asymmetry has been a particularly contentious topic in the past, with some (e.g. [34]) arguing that the presence of asymmetric vanes in the primary feathers of fossil birds indicates that they were powered flyers. Primary feathers with only slightly asymmetric vanes are still aeroelastically unstable [35]. A recently described troodontid dinosaur specimen further indicates that the presence of vane asymmetry may be the basal state for paravians [36]. It is therefore the evolution of more extreme vane asymmetry, rather than slight asymmetry, that was critical to avian flight.

Data on the stiffness of some fossil feather rachises indicate that the primary feathers would have been weaker in bending than comparable feathers in modern birds and suggesting that these taxa were incapable of the same flight gaits seen in modern birds [20,37]. Additional studies 
have looked at the molecular structure, genetics and bioarchitecture of feathers, suggesting that biomechanical features were present both at the morphological and molecular levels during the acquisition of flight $[38,39]$. Though it has recently been argued that bird feathers and pterosaur integumentary fibers may share an evolutionary origin [40,41], as they are not thought to have any aerodynamic role in pterosaurs, they are not considered further here.

Unlike modern birds with a single layer of primary feathers, Archaeopteryx appears to have had multiple layers. This layering may have forced a different performance profile than in modern birds [30] and it suggests an alternative system for the control of aeroelasticity that compensated for relatively symmetric primaries and comparatively thin rachises. The recently described Changyuraptor exhibited exceptionally long tail and hind limb feathers, which have been interpreted as pitch and yaw control structures respectively that would help control the speed during descent and landing [29]. Wind tunnel experiments and flight simulations of a feathered Microraptor model revealed that they would have been efficient at low-speed gliding, using all five feathered surfaces (two forewings, two hind limbs and a tail) as lifting surfaces, a distinctly different bauplan to extant birds $[24,42]$. This distributed control system made heavy use of multi-modal components: the tail, forelimbs, and hind limbs all had functions beyond flight propulsion and control. Such multi-modal systems are relevant to UAV applications where units are required to be generalists, fulfilling multiple tasks with limited human input.

\section{Membranes}

Most information on membrane wing dynamics in living systems comes from key experimental work with bats. Bats suspend their primary wing membranes across four digits, providing substantial support for tensioning via motions of the fingers. This allows their membranes to be relatively thin, yet dynamic and structurally complex. Bat wings contain muscles and elastin fibers that affect their compliance, dynamic responses to load, material properties and structural 
properties $[43,44]$. Although little work has been done on early bat flight, the shape of early bat wings indicates a flight style of undulating gliding-fluttering may be primitive, and that the tail membrane evolved early on as an additional airfoil [26].

Within pterosaurs, understanding of the structure and arrangement of the fibers in the membraneous wings $[12,45]$, a new model for the response to the wing under loading [21], and the position of the wings in steady flight [46] combine to give a much revised and enhanced picture of pterosaur flight capacity. Pterosaur flight membranes consisted of at least three distinct tissue layers with actinofibrils throughout $[12,45]$. These likely functioned in a structural manner by increasing the tensile strength and flexibility of the membrane [47] although their exact function is difficult to determine without knowing their composition $[12,45,46]$. Estimates of membrane tension in pterosaur wings, derived from aeroelastic limits and wing bone stiffness, suggest that these actinofibrils must have been keratinous to reinforce the membrane, significantly differing from the membranes of bats [48]. All fossils that have relevant portions preserved and undistorted show the membrane attaching to the lower leg or ankle [49].

Wind tunnel tests indicate that the pterosaur wing was likely adapted to generate and operate at relatively high lift coefficients [46]. As a result, pterosaurs were probably not well adapted to fly at high speeds but were instead efficient at low speed flight. This would have provided significant advantages during thermal soaring and allowed low-speed landings [46]. These factors also lower the energy requirements for launch at large body sizes. Optimization for slow, highly manoeuvrable flight is relevant to urban performance UAV markets (both commercial and military), where the environments are often highly cluttered and target surfaces for landing may be very small. As such, animals adapted to fly at high lift coefficients, both living and fossil, might have a great deal to offer engineers in terms of shape and material optimization. 
Mechanical considerations indicate that pterosaur wings must have had a concave posterior margin to avoid aeroelastic instability. Proper tensioning of membrane wings in pterosaurs would have been impossible with a convex posterior margin, because of the single-spar construction [50]. A theoretically most efficient wing shape would combine a lunate wingtip (supported by both soft tissue preservation [49] and osteology [21]) with anterior sweep to minimize induced drag and provide passive static stability [50]. It has been suggested that the largest pterosaurs were secondarily flightless (e.g. [51]), but more recent work suggests that the maximum launch-capable body mass for pterosaurs may have been quite high, owing to the high maximum lift coefficient of their wings and their potential for quadrupedal launch. Anatomical evidence combined with mechanical constraints suggests that the largest known pterosaurs, with wingspans of over 10 meters, were still not at a mechanical limit for launch and flight $[17,52,53]$. Detailed biomechanical studies comparing the largest pterosaurs with birds show that flying is easily possible and not limited until wingspans upwards of $15 \mathrm{~m}$, at the low flight speed predicted for pterosaurs [46,53]. It is actually launch that limits the maximum size of pterosaurs, and assuming a quadrupedal launch, this would be possible to approximately $12 \mathrm{~m}$ wingspans [53]. This is possible due to the large pectoral and flight musculature present in pterosaurs, making up approximately $40 \%$ of their total body mass $[54,55]$.

Pterosaurs possessed a respiratory system made up of a series of pulmonary air sacs, both in the main body cavity and subcutaneous air sacs in the wings of some [56] which may have influenced the cross-sectional of the wings and by extension wing performance. This results in wing bones frequently being hollow but not necessarily lighter than equivalent apneumatized bones [57]. Some large pterosaur wing bones are among the most pneumatic bones ever found, with perhaps $90 \%$ of the bone volume being filled with air [58]. These thin-walled pneumatic wing bones become more resistant to bending as the diameter of the bone increases, an important feature as the animal's mass increases and bending loads on the wings get larger [58]. However, 
additional data indicate that the wing bones of pterosaurs may not have been as light as previously thought, leading to new questions about mass estimation in pterosaurs [59].

\section{Challenges of flight}

The evolution of powered flight in animals ultimately includes three major components: the evolution of launch, the origin of a thrust-producing flight stroke, and the evolution of in-flight control. These characteristics are all interrelated and presumably evolved partly in parallel, but likely appeared somewhat piecemeal.

\section{Launch and Landing}

Launch and landing are critical phases of flight and are likely the limiting factors on maximum size for flying animals. The use of the walking limbs to initiate launch from a level surface is ubiquitous in flying animals. In small birds such as hummingbirds (Trochilidae), about 50\% of the launch force is derived from the legs [60] and for other birds often $80-90 \%$ of the launch is from leaping or running [61]. Some bats launch from the ground using quadrupedal leaping $[62,63]$. Ballistic launch is also fundamental to unpowered flyers - gliding mammals take off by leaping [64], and gliding snakes are the only snakes that can truly jump in the biomechanical sense [65], highlighting the importance of leaping for animal flight. Based on bone crosssectional properties, trackways, and comparisons with modern taxa, it has been hypothesized that many (if not most) pterosaurs probably also launched in a semi-ballistic fashion via quadrupedal leaping $[17,52]$. The use of a quadrupedal launch was likely an important factor that allowed for giant size in pterosaurs $[17,52,53]$. Their membrane wings also contributed to a higher maximum size limit by providing much higher maximum lift coefficients than the comparatively thick wings of birds. While the largest flying birds probably massed around $75 \mathrm{~kg}$, the largest 
pterosaurs likely massed nearly $300 \mathrm{~kg}[51,66]$. This difference highlights the substantially greater power:mass ratio during launch for a quadrupedal launcher compared with a bipedal launcher.

\section{Optimizing wing performance}

Flying vertebrates can optimize their wing performance to changing conditions by changing their wing shape in flight. In terms of morphing wing capacity, flying animals significantly outperform existing manufactured systems. Ratios of Lift to Drag (L:D) are important to soaring flight, as this sets the minimum glide angle. Birds, in particular, have significant morphing wing strategies to achieve improved L:D ratios while soaring. The effective aspect ratios of the wings of inland soaring birds (e.g. Harris's hawks) are higher than the anatomical values usually reported in the literature, because the use of tip slots increases the effective aspect ratio at low speeds $[67,68]$. As the wings of flying animals are not fixed, they can adjust the relative angle of sweep of the wings over a continuous range of positions to stabilize themselves in pitch. For those with compliant wings, an inboard reflex camber might also be a method of achieving pitch stability. Reflex camber occurs when the curvature of the wing reverses in part of the wing, forming an area where the upper surface of the wing is slightly concave, instead of the lower surface being concave. For the "inboard" case, this means that the part of the wing closest to the body is the section that is "flipped". This requires a compliant, morphing wing with complex control. Pterosaurs, in particular, seem to have had morphological traits that would enable them to utilize an inboard reflex camber, likely in conjunction with forward wing sweep [50]. These advantages and constraints have implications for both morphing wing designs in air vehicles and reconstructions of fossil taxa.

\section{Control}


Flight stability in animals has been achieved differently, in some respects, to that of most fixedwing aircraft. It is notable, for instance, that no living flying animals possess a vertical tail wing as utilized by modern traditional aircraft and vertical tails are almost unknown in the fossil record as well. Microraptorines possessed a pair of vertical wings on the hind limbs, but these were not placed nor shaped like the tail rigs on aircraft (and may have been dynamic control surfaces for turning, rather than stabilizing) [24,42]. Similarly, bats use the positioning of their tail membrane (uropatagium) to control the angle of attack and pitch [69].

The tail fan of living birds is a dynamic structure with the capacity to affect dynamic control of yaw, pitch, and roll although the tail is not necessary for flight control in birds. The tail fans of microraptorines emerged at the distal end of typically dinosaurian long, bony tail and may have been more specialised to pure pitch control [29], though the mass of the tail compared to birds may have provided counterbalancing functions. This multi-modality can provide a useful model for UAV systems that are also built to climb or cling to walls.

Regarding tails, it may be the fact that flying animals do not need vertical tails that may be of the most interest to engineers. Flying animals appear to make use of spanwise twist in the wing, thereby shedding the outboard ("tip") vortices slightly inboard (proximal) of the wing tip. This results in proverse yaw while turning, instead of adverse yaw [70]. As a result, animals do not require vertical tails or rudder-type elements for flight control. Such vertical tail rigs in fixed wing aircraft are quite costly. Utilizing lift distributions more akin to those of flying animals could provide exceptional efficiency gains [70]. While living animals will inevitably provide much of the data for this application, each group of vertebrate flyers has achieved the required span-wise twist slightly differently. The pterosaur solutions to this problem are only decipherable from the fossil record, however, since they have no living representatives. Furthermore, 
pterosaurs appear to have been exceptionally effective at controlling yaw and pitch, often with hardly any tail system at all. So much so, in fact, that many species could afford enormously expanded heads and/or massive cranial ornamentation.

\section{Future directions in Biology}

Early forms of flying animals were likely small, rare, with some level of reduced skeletal mass, and in inland arboreal environments - all major biases against producing fossils. As a result, the discovery of many intermediate forms in the origin of flight may be near fruitless. Many extinct flying lineages are known only from species that were fully flight capable with no early forms showing limited, or even lacking, flight $[3,26]$. However, future discoveries may fill these gaps, and further studies of the flight of early forms may constrain the possible macroevolutionary pathways (e.g. [71]).

In contrast to bats and pterosaurs, there is an extensive bird fossil record with numerous forms that had varying degrees of inferred flight capability [11,31,32]. As a result, the origin and evolution of feathers prior to the origin of flight are now known in detail $[41,72,73]$. There remains controversy over the origins of bird flight. Prior positions have often been one of a 'ground-up' progression to flapping flight from terrestrial ancestors, or a 'trees-down' from gliding, arboreal ancestors (although any animal that had reached the ground through gliding would need to gain height again and some form of flapping-climbing would integrate both hypotheses) $[74,75]$. Resolving these competing ideas is generating an ever better understanding of the functional anatomy of these animals (e.g. [25]) (Outstanding Questions).

\section{Future Directions in Engineering and Technology}

This new and enhanced level of understanding of flight in fossil animals is well timed to integrate with a major area of engineering - that of human constructed vehicles (Box 3). 
Increasingly engineers are turning to living organisms for inspiration of known evolutionary 'solutions' to mechanical problems. In the case of flight, engineers already look to extant birds, bats, and insects (though it is a young field) [76], but this overlooks the huge diversity of fossil forms and their different anatomical arrangements (Fig 2). Microraptor has been suggested as an option for fossil-inspired biomimicry [77], and pterosaurs have been briefly suggested as models [78] though neither has been investigated in detail.

Potential for future technology: Fossil forms provide a plethora of structures and integrated systems that can contribute to next-generation aircraft, robots, low-flutter fabrics, and ultra-light structures.

1. Novel methods for achieving aeroelastic stability. Inspiration: pterosaurs. Industry engineers have already begun to integrate information from palaeontologists into their models and consideration of biomimetic structures. Lockheed Martin - a global aerospace company- is including paleontological data in their training series. We note that pterosaur-based wing designs may be particularly good at controlling aeroelastic flutter. Engineering colleagues of the authors have already noted this feature in personat communications (G. Spedding, C. Palmer, J. Cunningham, pers. comms.). Pterosaurs are a particularly useful model for investigating aeroelastic control, because their single spar wing structure made aeroelastic control particularly critical to their flight performance. The specifics of actinofibril orientation, tissue layering, wing shape, and span-wise bone geometry in the wing were all involved in utilizing and controlling aeroelasticity in the wings of pterosaurs. For example, one author $(\mathrm{MBH})$ is currently involved in research with the Army Research Lab on this topic using pterosaurs and bats for inspiration.

2. Development of morphing wings. Inspiration: all flying vertebrates. Biologically inspired, compliant-wing ornithopters [76] also utilize the single-spar wing concept 
observed in pterosaurs, integrated with anatomical features of other flying animals. Future biological inspired designs will likely continue to be integrative, combining both fossil and extant animal features with traditional design concepts in mechanical engineering (such as adding pterosaur inspired control features to otherwise traditional aircraft - see [79]).

3. Utilizing Gaussian lift distributions. Inspiration: all flying vertebrates. The spanwise twist solution to adverse yaw used by flying animals eliminates their need for a vertical, yaw-correcting tail. Such tails are aerodynamically costly as they result in adverse lift and significant additional drag. Furthermore, alleviating the need for a standard vertical tail rig provides opportunities to design alternative tail rigs (if desired) that provide performance gains. Recent NASA experiments recovered up to $24 \%$ efficiency gains by using biomimetic wings based on this principle [70].

4. Self-launching and landing robots. Inspiration: multi-modality from birds, powerful ground launch from pterosaurs, and ceiling launching from bats. Flying animals excel at sudden take-off, landing on uneven terrain, and quickly/completely storing wings before and after flight. Mechanical designs currently perform much more poorly than animals these tasks. Biologically solutions may be a key guide to future improvements in UAV launch, landing, and storage. Pterosaur launch models may be particularly informative in this regard, as their takeoff system was effective over a very wide range of body sizes. With body masses ranging from a few tens of grams to well over $200 \mathrm{~kg}$ (and possibly over $300 \mathrm{~kg}$ ), pterosaurs overlapped much of the size range relevant to modern drones (The LaFlamme Aero Inc LX300, among the larger helicopter type drones, has a maximum takeoff mass of $300 \mathrm{~kg}$, for example). 
5. Unconventional control surfaces. Inspiration: microraptorines, pterosaurs. Winged, non-avian dinosaurs used an arrangement of four wings (with the set on the hind limbs likely being a vertical set that acted mostly in yaw and roll) as well as control from the tail [29], while pterosaurs have a biologically unique wing with a bony spar at the leading edge and a complex multi-layered membrane behind $[12,45,46,48]$ and a tail vane. As pterosaurs were the largest animals to fly, this is also a biologically successful morphology that provides useful insights for engineering questions [53,54].

6. Hybrid wings. Inspiration: Yi qi and Ambopteryx. These are the only feathered animals known with extensive membrane wings (Fig 2). A new array of biomimetic options is opened by the prospect of creating wings through a combination of compliant surfaces with stiff, sliding surfaces. Applications of these fundamentals will be an exciting challenge for engineers. Biologists will have opportunities to use evolutionary theory and fossil records to help explain the conditions under which a wing like that of $Y i$ qi and Ambopteryx may have evolved.

\section{Concluding remarks: Why use information from fossils to improve technology?}

Assessments of the flight performance of fossils forms have unique problems as specimens are often incomplete or not preserved in three dimensions. However, rising to the challenge of creating robust models of performance for fossil species yields unique insights and pushes the limits of flight research in fundamentally productive ways. Furthermore, the sheer diversity of form and phylogeny covered by fossil taxa (far beyond the small fraction of life currently extant) provides exciting and unique opportunities for expanding our understanding of biology and mechanics. It is possible to extract considerable information from extinct animals and the integration and synthesis of the fields of palaeontology, biomechanics and aeronautical 
engineering has enormous potential to generate new and critical knowledge to the understanding of each area, see Outstanding Questions.

\section{Box 1 - Types of flight}

Dozens of different lineages of vertebrates (extant and extinct) have evolved various ways of moving through the air with varying abilities. Biomechanists have defined multiple forms of flight in animals.

'Parachuting' is typically used for those animals that are passive fliers (i.e. are not flapping) that descend at an angle of greater than $45^{\circ}$ (i.e. they lose one or more units of height for each unit of horizontal length travelled [8]). Many animals have limited flight capability and may be engaged in little more than a controlled fall of slightly reduced speed (e.g. some squirrels [80]; frogs [81]; and geckos [82]).

'Gliding' is used for animals covering greater distances and descend at an angle less than $45^{\circ}$. This passive mode of flight is very common and includes species with considerably smaller glide angles (less sink relative to forward travel) than might be expected including snakes [65] and various primates [83] in addition to more 'traditional' gliders such as the lizard Draco, colugos (Dermoptera) and marsupial sugar gliders (Petaurus breviceps).

Soaring is a form of passive flight (though as with gliding, is often a behaviour of powered fliers) which involves using external sources of lift. Soaring flight extracts energy from the movement of air to gain altitude or speed. Soaring most often involves the use of thermals (e.g. vultures, Accipitridae, Cathartidae) or the action of wind gradients (e.g. albatross, Diomedeidae), which are used to gain height and glide to a new location making this a very efficient form of travel. Powered flight relates to those animals engaged in flapping flight that can increase their height in still air. The only known vertebrate clades to have evolved powered flight are the birds (Aves), 
bats (Chiroptera) and the extinct pterosaurs (Pterosauria). All three are highly diverse and longlived clades.

Hovering relates to animals being able to remain at one point in the air. This may be achieved through powered flight in still air (e.g. hummingbirds, Trochilidae) or passively with air moving over the wings (e.g. kestrels, Falco).

Other forms of locomotion are known such as flying fish that do not flap their 'wings' (the pectoral fins) but use them to passively generate lift while the tail paddles in the water to generate thrust. Powered fliers may exhibit different gaits with varied patterns and style of wingbeats.

\section{Box 2 - Vertebrate fliers in the fossil record}

The fossil record contains numerous taxa that are relatives of extant fliers (fossil birds and bats, but also for example flying fish [84]) but also those that apparently had converged on near identical planforms with modern taxa (Fig I, Fig II). The small gliding lizard Draco uses a flap of skin supported by extended ribs to glide, but this planform is also known from a separate lineage of Triassic reptiles including Icarosaurus [85], and a Jurassic gliding mammal, Volaticotherium is known from China [10] which flew with a membrane very similar to that employed by various extant mammals including flying squirrels (Pteromyini) and marsupial sugar gliders.

However, other forms appear in the fossil record that are quite unknown among extant animals. The small Triassic reptile Sharovipteryx (Fig IIA) was apparently a glider that had extensive membranes between its long legs forming a delta-wing, greatly reduced arms, but a small set of anterior canards supported by the hyoids [86]. 
Non-avialan dinosaurs also provide additional planforms. Various small, feathered dinosaurs that were close to the origin of birds included forms that apparently could parachute or glide based on wings on the forelimbs and hindlimbs which produced a combination of lifting and steering surfaces, bolstered by a broad flap of feathers on the tail (Microraptor [24,42] (Fig IIB), Anchiornis [11]). Finally, the recently discovered Yi and Ambopteryx show a melange of features - notably an enlarged wrist bone supporting an apparently small membranous wing, but also a flight surface composed of feathers [27,28] (Fig. 2).

Finally, the Mesozoic pterosaurs were powered fliers that had a complex and multi-layered membranous wing supported by a single spar (the arm and an elongated fourth finger).

Additional smaller membranes to the fore and rear assisted with control. The largest pterosaurs reached in excess of $10 \mathrm{~m}$ in wingspan, $250 \mathrm{~kg}$ and had skulls perhaps $3 \mathrm{~m}$ long, vastly exceeding any other known flying animal in size and weight (Fig IIC) [3].

Although some limited attempts have been made to build vehicles based on pterosaurs, they remain an overlooked model for flying machines, and the other taxa provide additional novel planforms which may be exploited. $Y i$ and Ambopteryx in particular show that truly novel and, importantly, unpredicted, combinations of flying features can still be discovered.

\section{Box 3: Key areas mechanically}

There are a number of anatomic and functional aspects of extinct organisms that can potentially be used to improve the design of existing aircraft or form the basis of future ones. The folding, multifunctional, single spar, and membranous wing of pterosaurs provides an excellent model for a multi-modal wing concept that has significant morphing capacity. Such wings scaled effectively, as well: flying juveniles of the smallest pterosaurs were the size of songbirds, while 
the largest adults had wingspans in excess of 10 meters. The combination of multiple spars supporting both a membrane and feathers, as in $Y i$ (Fig 2), provides a model for combining relatively stiff wing sections with highly compliant ones, all integrated such that the wing was still foldable. Such wings can function in a fixed position but can also change shape and performance to respond to varying conditions, alleviate loads from gusts, or to fold into a terrestrial support position. Similarly, the shape, position and construction of control surfaces used by pterosaurs or Sharovipteryx provide examples of successful compliant control surfaces. Compliant surfaces are inherently dynamic and can produce high lift coefficients, traits of importance for designs intended to carry heavy loads or work in unpredictable environments.

The construction of the wing, such as the multiple layers of stiffening fibers combined with muscle fibers (e.g. something which can change the shape and camber of the wing) in pterosaurs provide additional means to alter wings, or even sections of wing, during flight to improve control or performance. The formation of a high-performance structure using composites of comparatively simple subunits is a common theme in animal morphology, and it is particularly true of animal wings. Thanks to high-fidelity preservation of pterosaurs from Brazil, China, and Germany, it is possible to examine these composite morphologies even in fossil flyers.

Wake modulation is a common feature of living flyers, and it appears to have been important for extinct flyers, as well. Fibers of various types are seen on the bodies of flying animals (both powered and unpowered) which can help create a well-connected boundary layer and reduce drag. Some pterosaurs show fibers on the wing analogous to those feathers of owls that reduce sound [3].

\section{Outstanding questions}


How does the evolution of control fit into the scheme of biological flight? Future work needs to examine whole animals, especially control elements beyond the main wings (e.g. nonpterodactyloid pterosaur tails, dromaeosaur tails).

How does the evolution of powered and unpowered flight compare? Work has historically focused on powered flight, but obligate gliders also utilize dynamics of interest. Of interest here will be tests of the hypothesis that an obligate glider stage is an intermediate in the evolution of powered flight. To date, this is a highly contentious concept.

\section{How do flying vertebrates balance the requirements of powered flight against other} developmental, ecological, and morphological constraints? All flyers maintain feeding structures, reproductive structures, and a basic body plan set by strict developmental constraints. Despite the trade-offs of aerial locomotion, some flying animals also balance(d) extreme morphologies unrelated to flight. For example, many pterosaurs had enormously enlarged heads and/or necks, which would have demanded novel wing positions and/or body density distributions to solve problems of pitch.

How do flying animals transition between the air and other substrates? Beyond sustained aerial locomotion, take-off and landing are also critical components of flight and have rarely been studied. There is much to learn about launch mechanics, landing dynamics, and wing folding/unfolding. These are highly likely to yield new insights applicable to engineering and mechanical design, because sudden takeoff, landing on uneven surfaces, and complex wing folding are areas where animals excel but human designs are still relatively basic.

What are the mechanical properties of animal wings, and can we estimate these properties for fossil taxa? Few projects have quantitatively estimated the wing material properties in fossil vertebrates. Understanding how high performance biological materials evolved will provide important biomechanical context in extant species. 


\section{References}

1 Burleigh, J.G. et al. (2015) Building the avian tree of life using a large-scale, sparse supermatrix. Mol. Phylogenet. Evol. 84, 53-63

2 Jones, K.E. et al. (2002) A phylogenetic supertree of the bats (Mammalia: Chiroptera). Biol. Rev. Camb. Philos. Soc. 77, S1464793101005899

3 Witton, M.P. (2013) Pterosaurs: natural history, evolution, anatomy, Princeton University Press.

4 Altshuler, D.L. et al. (2015) The biophysics of bird flight: functional relationships integrate aerodynamics, morphology, kinematics, muscles, and sensors. Can. J. Zool. 93, 961-975

5 Swartz, S.M. and Konow, N. (2015) Advances in the study of bat flight: the wing and the wind. Can. J. Zool. 93, 977-990

6 Hedrick, T.L. et al. (2015) Recent developments in the study of insect flight 1. Can. J. Zool. 93, 925-943

7 Middleton, K.M. and English, L.T. (2015) Challenges and advances in the study of pterosaur flight. Can. J. Zool. 93, 945-959

8 Rayner, J.M. V (1981) Flight adaptations in vertebrates. Symp. Zool. Soc. London 48, $137-172$

9 Norberg, U.M. (1985) Evolution of Vertebrate Flight: An Aerodynamic Model for the Transition from Gliding to Active Flight. Am. Nat. 126, 303-327

10 Meng, J. et al. (2006) A Mesozoic gliding mammal from northeastern China. Nature 444, 889-893

11 Xu, X. et al. (2009) A new feathered maniraptoran dinosaur fossil that fills a morphological gap in avian origin. Sci. Bull. 54, 430-435

12 Kellner, A.W.A. et al. (2010) The soft tissue of Jeholopterus (Pterosauria, Anurognathidae, Batrachognathinae) and the structure of the pterosaur wing membrane. Proc. R. Soc. B Biol. Sci. 277, 321-329

13 Hone, D.W.E. et al. (2010) The Extent of the Preserved Feathers on the Four-Winged Dinosaur Microraptor gui under Ultraviolet Light. PLoS One 5, e9223

14 Bergmann, U. et al. (2010) Archaeopteryx feathers and bone chemistry fully revealed via synchrotron imaging. Proc. Natl. Acad. Sci. U. S. A. 107, 9060-5

15 Koehl, M.A.R. et al. (2011) Using Physical Models to Study the Gliding Performance of Extinct Animals. Integr. Comp. Biol. 51, 1002-1018

16 Burgers, P. and Chiappe, L.M. (1999) The wing of Archaeopteryx as a primary thrust generator. Nature 399, 60-62

17 Habib, M.B. (2008) Comparative evidence for quadrupedal launch in pterosaurs.

Zitteliana B 28, 159-166 
18 Walker, A.D. (1977) Evolution of the pelvis in birds and dinosaurs. In Problems in Vertebrate Evolution (Andrews, S. M. et al., eds), pp. 319-357, Linnaean Society

19 Li, Q. et al. (2012) Reconstruction of Microraptor and the Evolution of Iridescent Plumage. Science (80-. ). 335, 1215-1219

20 Nudds, R.L. and Dyke, G.J. (2010) Narrow Primary Feather Rachises in Confuciusornis and Archaeopteryx Suggest Poor Flight Ability. Science (80-. ). 328, 887-889

21 Hone, D.W.E. et al. (2015) The wingtips of the pterosaurs: Anatomy, aeronautical function and ecological implications. Palaeogeogr. Palaeoclimatol. Palaeoecol. 440, 431-439

22 Elgin, R.A. et al. (2008) Aerodynamic characters of the cranial crest in Pteranodon. Zitteliana B28, 167-174

23 Stein, K. et al. (2008) The aerodynamics of the British Late Triassic Kuehneosauridae. Palaeontology 51, 967-981

24 Dyke, G. et al. (2013) Aerodynamic performance of the feathered dinosaur Microraptor and the evolution of feathered flight. Nat. Commun. 4, 2489

25 Dial, K.P. et al. (2008) A fundamental avian wing-stroke provides a new perspective on the evolution of flight. Nature 451, 985-989

26 Simmons, N.B. et al. (2008) Primitive Early Eocene bat from Wyoming and the evolution of flight and echolocation. Nature 451, 818-821

$27 \mathrm{Xu}$, X. et al. (2015) A bizarre Jurassic maniraptoran theropod with preserved evidence of membranous wings. Nature 521, 70-73

28 Wang, M. et al. (2019) A new Jurassic scansoriopterygid and the loss of membranous wings in theropod dinosaurs. Nature 569, 256-259

29 Han, G. et al. (2014) A new raptorial dinosaur with exceptionally long feathering provides insights into dromaeosaurid flight performance. Nat. Commun. 5, 4382

30 Longrich, N.R. et al. (2012) Primitive Wing Feather Arrangement in Archaeopteryx lithographica and Anchiornis huxleyi. Curr. Biol. 22, 2262-2267

$31 \mathrm{Xu}, \mathrm{X}$. et al. (2014) An integrative approach to understanding bird origins. Science 346, $1253293-1253293$

32 Brusatte, S.L. et al. (2015) The Origin and Diversification of Birds. Curr. Biol. 25, R888R898

33 Brusatte, S.L. (2017) A Mesozoic Aviary. Science 355, 792-794

34 Feduccia, A. (1999) The Origin and Evlution of Birds, Yale University Press.

35 Feo, T.J. et al. (2015) Barb geometry of asymmetrical feathers reveals a transitional morphology in the evolution of avian flight. Proc. R. Soc. B Biol. Sci. 282, 2014286420142864

$36 \mathrm{Xu}, \mathrm{X}$. et al. (2017) Mosaic evolution in an asymmetrically feathered troodontid dinosaur 
with transitional features. Nat. Commun. 8, 14972

37 Wang, X. et al. (2012) Size scaling and stiffness of avian primary feathers: implications for the flight of Mesozoic birds. J. Evol. Biol. 25, 547-555

38 Pan, Y. et al. (2019) The molecular evolution of feathers with direct evidence from fossils. Proc. Natl. Acad. Sci. U. S. A. 116, 3018-3023

39 Chang, W.-L. et al. (2019) The Making of a Flight Feather: Bio-architectural Principles and Adaptation. Cell 179, 1409-1423.e17

40 Yang, Z. et al. (2019) Pterosaur integumentary structures with complex feather-like branching. Nat. Ecol. Evol. 3, 24-30

41 Benton, M.J. et al. (2019) The Early Origin of Feathers. Trends Ecol. Evol. 34, 856-869

42 Evangelista, D. et al. (2014) Aerodynamic Characteristics of a Feathered Dinosaur Measured Using Physical Models. Effects of Form on Static Stability and Control Effectiveness. PLoS One 9, e85203

43 Cheney, J.A. et al. (2014) Membrane muscle function in the compliant wings of bats. Bioinspir. Biomim. 9, 025007

44 Cheney, J.A. et al. (2015) A wrinkle in flight: the role of elastin fibres in the mechanical behaviour of bat wing membranes. J. R. Soc. Interface 12, 20141286-20141286

45 Frey, E. et al. (2003) New specimens of Pterosauria (Reptilia) with soft parts with implications for pterosaurian anatomy and locomotion. In Evolution and Palaeobiology of Pterosaurs 217 (Buffetaut, E. and Mazin, J.-M., eds), pp. 233-266, Geological Society of London Special Publications

46 Palmer, C. (2011) Flight in slow motion: aerodynamics of the pterosaur wing. Proc. $R$. Soc. London B Biol. Sci. 278, 1881-1885

47 Bennett, S.C. (2000) Pterosaur flight: the role of actinofibrils in wing function. Hist. Biol. $14,255-284$

48 Palmer, C. (2017) Inferring the properties of the pterosaur wing membrane. In New Perspectives on Pterosaur Palaeobiology 455 (Hone, D. W. E. et al., eds), Geological Society of London Special Publications

49 Elgin, R.A. et al. (2011) The extent of the pterosaur flight membrane. Acta Palaeontol. Pol. 56, 99-111

50 Palmer, C. and Dyke, G. (2012) Constraints on the wing morphology of pterosaurs. Proc. R. Soc. B Biol. Sci. 279, 1218-1224

51 Henderson, D.M. (2010) Pterosaur body mass estimates from three-dimensional mathematical slicing. J. Vertebr. Paleontol. 30, 768-785

52 Witton, M.P. and Habib, M.B. (2010) On the size and flight diversity of giant pterosaurs, the use of birds as pterosaur analogues and comments on pterosaur flightlessness. PLoS One 5, e13982

53 Palmer, C. (2016) Flexible fliers: the flight of pterosaurs. University of Bristol, PhD 
Thesis. Available at http://colinpalmer.eu/pterowing/phd/

54 Strang, K.A. et al. (2009) Efficient flight of pterosaurs - an unsteady aerodynamic approach. 47th AIAA Aerospace Sciences Meeting (Proceedings), pp. 1-37

55 Martin-Silverstone, E. (2017) Insights into mass estimation, pneumaticity, and anatomy of pterosaurs: implications for locomotion. University of Southampton, PhD Thesis.

Available at https://eprints.soton.ac.uk/416889/

56 Claessens, L.P.A.M. et al. (2009) Respiratory evolution facilitated the origin of pterosaur flight and aerial gigantism. PLoS One 4, e4497

57 Dumont, E.R. (2010) Bone density and the lightweight skeletons of birds. Proc. R. Soc. B Biol. Sci. 277, 2193-2198

58 Martin, E.G. and Palmer, C. (2014) Air space proportion in pterosaur limb bones using computed tomography and its implications for previous estimates of pneumaticity. PLoS One 9, e97159

59 Martin, E.G. and Palmer, C. (2014) A novel method of estimating pterosaur skeletal mass using computed tomography scans. J. Vertebr. Paleontol. 34, 1466-1469

60 Tobalske, B.W. et al. (2004) Take-off mechanics in hummingbirds (Trochilidae). J. Exp. Biol. 207, 1345-1352

61 Earls, K.D. (2000) Kinematics and mechanics of ground take-off in the starling Sturnis Sturnus vulgaris and the quail Coturnix coturnix. J. Exp. Biol. 203, 725-739

62 Schutt, W.A.J. et al. (1997) The dynamics of flight-initiating jumps in the common vampire bat Desmodus rotundus. J. Exp. Biol. 203, 725-739

63 Riskin, D.K. and Hermanson, J.W. (2005) Independent evolution of running in vampire bats. Nature 434, 292

64 Paskins, K.E. et al. (2007) Take-off and landing forces and the evolution of controlled gliding in northern flying squirrels Glaucomys sabrinus. J. Exp. Biol. 210, 1413-1423

65 Socha, J.J. et al. (2005) A 3-D kinematic analysis of gliding in a flying snake, Chrysopelea paradisi. J. Exp. Biol. 208, 1817-33

66 Witton, M.P. (2008) A new approach to determining pterosaur body mass and its implications for pterosaur flight. Zitteliana B28, 143-159

67 Tucker, V.A. (1993) Gliding birds: reduction of induced drag by wing tip slots between the primary feathers. J. Exp. Biol. 180, 285-310

68 Alexander, D. (2002) Nature's Flyers: Birds, Insects, and the Biomechanics of Flight, Hopkins University Press.

69 Gardiner, J.D. et al. (2011) An association between ear and tail morphologies of bats and their foraging style. Can. J. Zool. 89, 90-99

70 Bowers, A.H. et al. (2016) On Wings of the Minimum Induced Drag: Spanload Implications for Aircraft and Birds. NASA Tech. Publ. at <https://ntrs.nasa.gov/search.jsp?R=20160003578> 
71 Zheng, X. et al. (2013) Hind wings in Basal birds and the evolution of leg feathers. Science 339, 1309-12

72 Prum, R.O. and Brush, A.H. (2002) The Evolutionary Origin And Diversification Of Feathers. Q. Rev. Biol. 77, 261-295

73 Norell, M.A. and Xu, X. (2005) Feathered Dinosaurs. Annu. Rev. Earth Planet. Sci. 33, 277-299

74 Dial, K.P. (2003) Wing-Assisted Incline Running and the Evolution of Flight. Science 299, 402-404

75 Padian, K. and Chiappe, L.M. (1998) The origin and early evolution of birds. Biol. Rev. Camb. Philos. Soc. 73, S0006323197005100

76 Ward, T.A. et al. (2015) A Review of Biomimetic Air Vehicle Research: 1984-2014. Int. J. Micro Air Veh. 7, 375-394

77 Shahid, F. et al. (2019) Design of flying robots inspired by the evolution of avian flight. Proc. Inst. Mech. Eng. Part C J. Mech. Eng. Sci. DOI: 10.1177/0954406219861995

78 Zakaria, M.Y. et al. (2015) Design Optimization of Flapping Ornithopters: The Pterosaur Replica in Forward Flight. DOI: 10.2514/1.C033154

79 Roberts, B. et al. (2011) Flight dynamics of a pterosaur-inspired aircraft utilizing a variable-placement vertical tail. Bioinspir. Biomim. 6, 026010

80 Essner, R.L. (2002) Three-dimensional launch kinematics in leaping, parachuting and gliding squirrels. J. Exp. Biol. 205, 2469-2477

81 Stewart, M.M. (1985) Arboreal Habitat Use and Parachuting by a Subtropical Forest Frog. J. Herpetol. 19, 391-401

82 Russell, A.P. (1979) The origin of parachuting locomotion in gekkonid lizards (Reptilia: Gekkonidae). Zool. J. Linn. Soc. 65, 233-249

83 Demes, B. et al. They seem to glide. Are there aerodynamic effects in leaping prosimian primates? , Zeitschrift für Morphologie und Anthropologie. (1991), E. Schweizerbart'sche Verlagsbuchhandlung, 373-385

84 Xu, G.-H. et al. (2012) A new stem-neopterygian fish from the Middle Triassic of China shows the earliest over-water gliding strategy of the vertebrates. Proc. R. Soc. B Biol. Sci. 280, 20122261-20122261

85 Colbert, E.H. (1970) The Triassic gliding reptile Icarosaurus. Bull. Am. Museum Nat. Hist. $143,85-142$

86 Dyke, G.J. et al. (2006) Flight of Sharovipteryx mirabilis: the world's first delta-winged glider. J. Evol. Biol. 19, 1040-1043 


\section{Figure Captions:}

Figure 1: Examples of the three main wing morphologies in vertebrate flight. A) Schematic drawing of a bird, bat and pterosaur wing showing homologous bones and wing outlines. Image by Mark Witton, used with permission. B) Fossils of vertebrates capable of powered flight. L-R: the early bird Archaeopteryx (wingspan c. $60 \mathrm{~cm}$ ), the extinct bat Palaeochiropteryx (wingspan c. $30 \mathrm{~cm}$ ) and the small pterosaur Aerodactylus (wingspan c. $50 \mathrm{~cm}$ ). f, feathers; lw, left wing; m, membrane; rw, right wing; sk, skull.

Figure 2: The non-avian dinosaur $Y i$ (left, fossil photo credit Xu Xing, used with permission; right, life reconstruction by Emily Willoughby, used with permission). This animal has an enlarged wrist element (the styliform element) and spread fingers supporting a membranous wing, but also possesses feathers (c. $50 \mathrm{~cm}$ wingspan). Such a combination is rare and unknown elsewhere in nature aside from its close relative Ambopteryx and could be copied with a biomimetic aircraft. f, feathers; lw, left wing; m, membrane; rw, right wing; se, styliform element; sk, skull.

Figure I (inside Box 2): Examples of non-powered flying vertebrates from the fossil record. From L-R: the gliding reptile Xianglong (wingspan c. $9 \mathrm{~cm}$, image from Mick Ellison, used with permission), the Triassic flying fish Potanichthys (length c. $10 \mathrm{~cm}$, image from Xu Guang-Hui, used with permission), and the Jurassic gliding mammal Volaticotherium (wingspan c. $16 \mathrm{~cm}$, image from Meng Jin, used with permission). f, feathers; lh, left humerus; lw, left wing; m, membrane; r, rib; rh, right humerus; rw, right wing; sk, skull.

Figure II (inside Box 2): Examples and associated reconstructions of unique flying vertebrates from the fossil record. A) the bizarre delta-winged reptile Sharovipteryx (legspan c. $15 \mathrm{~cm}$ ). Fossil image (left) from Nicholas C. Fraser, used with permission. Life reconstruction (right) by Mark Witton, used with permission. B) the 'four-winged' non-avian dinosaur Microraptor 
(wingspan c. $70 \mathrm{~cm}$ ). Fossil image (left) from Xu Xing, used with permission. Life reconstruction (right) by David Krentz, used with permission. C) Life reconstruction of the giant pterosaur Quetzalcoatlus northropi (wingspan c. 11 m), by David Krentz, used with permission. f, feathers; hl, hindlimbs; lw, left wing; m, membrane; rw, right wing; sk, skull. 


\section{Glossary}

Actinofibrils: slender structural filaments found in the membranes of pterosaur wings.

Aeroelasticity: study of the interaction between aerodynamic forces and non-rigid structures.

Angle of sweep: the angle at which the wing is directed backwards from its root, rather than at right angles to the body.

Apneumatic: non-pneumatic (air-filled), specifically referring to bones that are not filled with air.

Aspect ratio: the length of the wing divided by the average chord, typically calculated as the square of the span divided by the total wing area. High aspect ratio wings are proportionally long and thin, low aspect ratio are short and broad.

Ballistic launch: undergoing a jumping or bouncing launch.

Biomimetic: using nature or the natural world as inspiration to solve human problems such as designs.

Camber: the cord-wise curvature of a wing. This primarily affects the effective angle of attack, such that a cambered wing has a higher coefficient of lift than an uncambered one (i.e. it produces more lift per unit of wing area at any given airspeed).

Compliance: in material sciences, the inverse of stiffness.

Drag: the component of a fluid force that is aligned parallel to the flow. For a flying animal, this will primarily be a measure of resistance to movement through the air.

Lift: the component of a fluid force that is aligned perpendicular to the flow. For a flying animal, this will provide most weight support and thrust.

Lift coefficient: a dimensionless coefficient used in aerodynamics to compare the complex aspects related to an airfoil's performance. It takes into account the density of the fluid, the velocity of travel, and the size (area) of the wing.

Non-avialan dinosaurs: the traditional definition of dinosaurs, meaning all dinosaurs that do not include the flying avian dinosaurs, birds.

Phylogenetics: the study of how species are related to each other and the evolutionary relationships within groups of organisms.

Pitch: the position or rotation of an object about the horizontal axis.

Pneumatic: air-filled, specifically related to bones that are filled with air rather than marrow.

Powered flight: the process in which an object moves through the air without contacting the surface (flight), by means of generating a propulsive thrust (powered) rather than by merely exploiting lift generating surfaces and air such as in gliding or soaring.

Rachis: the main shaft of a feather.

Roll: the position or rotation of an object about the longitudinal axis.

Subcutaneous: under the skin, rather than within muscles or organs. 
Tensile strength: the capacity of a structure to withstand loads that elongate or stretch, the opposite of compressive strength.

Vane asymmetry: the tendency for some feathers to have one side of the rachis have longer barbs than those of the other, making the feather asymmetrical.

Yaw: The position or rotation of an object about the vertical axis. 


\section{Highlights}

Powered flight evolved independently in three groups of vertebrates: birds, bats, and extinct flying reptiles known as pterosaurs.

The flight surface in flying vertebrates is highly morphologically variable, ranging from a feathered wing with highly adapted flight feathers (birds) to elongated digits with membrane stretched between (bats) to a single elongated digit with a large membrane stretched to the body (pterosaurs).

More unique morphologies are now known from the fossil record with hybrid structures including membraneous feathered wings and four-winged biplane-like animals.

The fossil record provides ever increasing examples for inspiration in mechanical design and without its use we ignore 250 million years of gliding and flying morphologies.

Future biomechanical studies of unique fossil morphologies may impact mechanical design. 


\section{Outstanding questions}

How does the evolution of control fit into the scheme of biological flight? Future work needs to examine whole animals, especially control elements beyond the main wings (e.g. non-pterodactyloid pterosaur tails, dromaeosaur tails).

\section{How does the evolution of powered and unpowered flight compare? Work has} historically focused on powered flight, but obligate gliders also utilize dynamics of interest. Of interest here will be tests of the hypothesis that an obligate glider stage is an intermediate in the evolution of powered flight. To date, this is a highly contentious concept.

\section{How do flying vertebrates balance the requirements of powered flight against other} developmental, ecological, and morphological constraints? All flyers maintain feeding structures, reproductive structures, and a basic body plan set by strict developmental constraints. Despite the trade-offs of aerial locomotion, some flying animals also balance(d) extreme morphologies unrelated to flight. For example, many pterosaurs had enormously enlarged heads and/or necks, which would have demanded novel wing positions and/or body density distributions to solve problems of pitch.

\section{How do flying animals transition between the air and other substrates? Beyond} sustained aerial locomotion, take-off and landing are also critical components of flight and have rarely been studied. There is much to learn about launch mechanics, landing dynamics, and wing folding/unfolding. These are highly likely to yield new insights applicable to engineering and mechanical design, because sudden takeoff, landing on uneven surfaces, and complex wing folding are areas where animals excel but human designs are still relatively basic. 
What are the mechanical properties of animal wings, and can we estimate these properties for fossil taxa? Few projects have quantitatively estimated the wing material properties in fossil vertebrates. Understanding how high performance biological materials evolved will provide important biomechanical context in extant species. 


\section{Box 1 - Types of flight}

Dozens of different lineages of vertebrates (extant and extinct) have evolved various ways of moving through the air with varying abilities. Biomechanists have defined multiple forms of flight in animals.

'Parachuting' is typically used for those animals that are passive fliers (i.e. are not flapping) that descend at an angle of greater than $45^{\circ}$ (i.e. they lose one or more units of height for each unit of horizontal length travelled [8]). Many animals have limited flight capability and may be engaged in little more than a controlled fall of slightly reduced speed (e.g. some squirrels [80]; frogs [81]; and geckos [82]).

'Gliding' is used for animals covering greater distances and descend at an angle less than $45^{\circ}$. This passive mode of flight is very common and includes species with considerably smaller glide angles (less sink relative to forward travel) than might be expected including snakes [65] and various primates [83] in addition to more 'traditional' gliders such as the lizard Draco, colugos (Dermoptera) and marsupial sugar gliders (Petaurus breviceps). Soaring is a form of passive flight (though as with gliding, is often a behaviour of powered fliers) which involves using external sources of lift. Soaring flight extracts energy from the movement of air to gain altitude or speed. Soaring most often involves the use of thermals (e.g. vultures, Accipitridae, Cathartidae) or the action of wind gradients (e.g. albatross, Diomedeidae), which are used to gain height and glide to a new location making this a very efficient form of travel.

Powered flight relates to those animals engaged in flapping flight that can increase their height in still air. The only known vertebrate clades to have evolved powered flight are the birds (Aves), bats (Chiroptera) and the extinct pterosaurs (Pterosauria). All three are highly diverse and long-lived clades. 
Hovering relates to animals being able to remain at one point in the air. This may be achieved through powered flight in still air (e.g. hummingbirds, Trochilidae) or passively with air moving over the wings (e.g. kestrels, Falco).

Other forms of locomotion are known such as flying fish that do not flap their 'wings' (the pectoral fins) but use them to passively generate lift while the tail paddles in the water to generate thrust. Powered fliers may exhibit different gaits with varied patterns and style of wingbeats. 


\section{Box 2 - Vertebrate fliers in the fossil record}

The fossil record contains numerous taxa that are relatives of extant fliers (fossil birds and bats, but also for example flying fish [84]) but also those that apparently had converged on near identical planforms with modern taxa (Fig I, Fig II). The small gliding lizard Draco uses a flap of skin supported by extended ribs to glide, but this planform is also known from a separate lineage of Triassic reptiles including Icarosaurus [85], and a Jurassic gliding mammal, Volaticotherium is known from China [10] which flew with a membrane very similar to that employed by various extant mammals including flying squirrels (Pteromyini) and marsupial sugar gliders.

However, other forms appear in the fossil record that are quite unknown among extant animals. The small Triassic reptile Sharovipteryx (Fig IIA) was apparently a glider that had extensive membranes between its long legs forming a delta-wing, greatly reduced arms, but a small set of anterior canards supported by the hyoids [86].

Non-avialan dinosaurs also provide additional planforms. Various small, feathered dinosaurs that were close to the origin of birds included forms that apparently could parachute or glide based on wings on the forelimbs and hindlimbs which produced a combination of lifting and steering surfaces, bolstered by a broad flap of feathers on the tail (Microraptor [24,42] (Fig IIB), Anchiornis [11]). Finally, the recently discovered $Y i$ and Ambopteryx show a melange of features - notably an enlarged wrist bone supporting an apparently small membranous wing, but also a flight surface composed of feathers [27,28] (Fig. 2).

Finally, the Mesozoic pterosaurs were powered fliers that had a complex and multi-layered membranous wing supported by a single spar (the arm and an elongated fourth finger). Additional smaller membranes to the fore and rear assisted with control. The largest 
pterosaurs reached in excess of $10 \mathrm{~m}$ in wingspan, $250 \mathrm{~kg}$ and had skulls perhaps $3 \mathrm{~m}$ long, vastly exceeding any other known flying animal in size and weight (Fig IIC) [3].

Although some limited attempts have been made to build vehicles based on pterosaurs, they remain an overlooked model for flying machines, and the other taxa provide additional novel planforms which may be exploited. $Y i$ and Ambopteryx in particular show that truly novel and, importantly, unpredicted, combinations of flying features can still be discovered. 


\section{Box 3: Key areas mechanically}

There are a number of anatomic and functional aspects of extinct organisms that can potentially be used to improve the design of existing aircraft or form the basis of future ones. The folding, multifunctional, single spar, and membranous wing of pterosaurs provides an excellent model for a multi-modal wing concept that has significant morphing capacity. Such wings scaled effectively, as well: flying juveniles of the smallest pterosaurs were the size of songbirds, while the largest adults had wingspans in excess of 10 meters. The combination of multiple spars supporting both a membrane and feathers, as in $Y i$ (Fig 2), provides a model for combining relatively stiff wing sections with highly compliant ones, all integrated such that the wing was still foldable. Such wings can function in a fixed position but can also change shape and performance to respond to varying conditions, alleviate loads from gusts, or to fold into a terrestrial support position. Similarly, the shape, position and construction of control surfaces used by pterosaurs or Sharovipteryx provide examples of successful compliant control surfaces. Compliant surfaces are inherently dynamic and can produce high lift coefficients, traits of importance for designs intended to carry heavy loads or work in unpredictable environments.

The construction of the wing, such as the multiple layers of stiffening fibers combined with muscle fibers (e.g. something which can change the shape and camber of the wing) in pterosaurs provide additional means to alter wings, or even sections of wing, during flight to improve control or performance. The formation of a high-performance structure using composites of comparatively simple subunits is a common theme in animal morphology, and it is particularly true of animal wings. Thanks to high-fidelity preservation of pterosaurs from Brazil, China, and Germany, it is possible to examine these composite morphologies even in fossil flyers. 
Wake modulation is a common feature of living flyers, and it appears to have been important for extinct flyers, as well. Fibers of various types are seen on the bodies of flying animals (both powered and unpowered) which can help create a well-connected boundary layer and reduce drag. Some pterosaurs show fibers on the wing analogous to those feathers of owls that reduce sound [3]. 
A

\section{Bird}

Digits I-III (mostly fused)

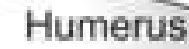

Uina

\section{Fused carpal and}

metacarpal bones

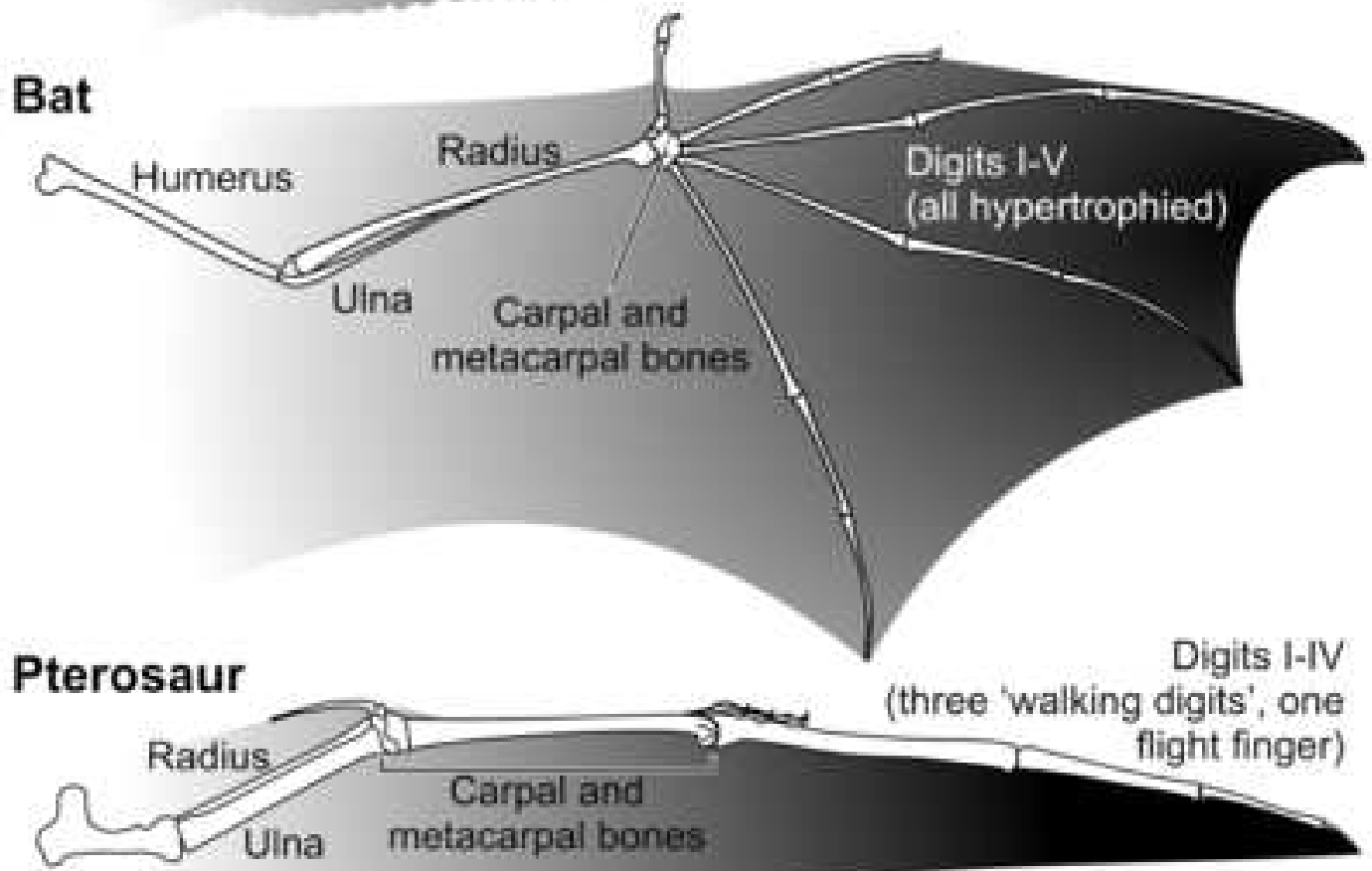

Humerus

B
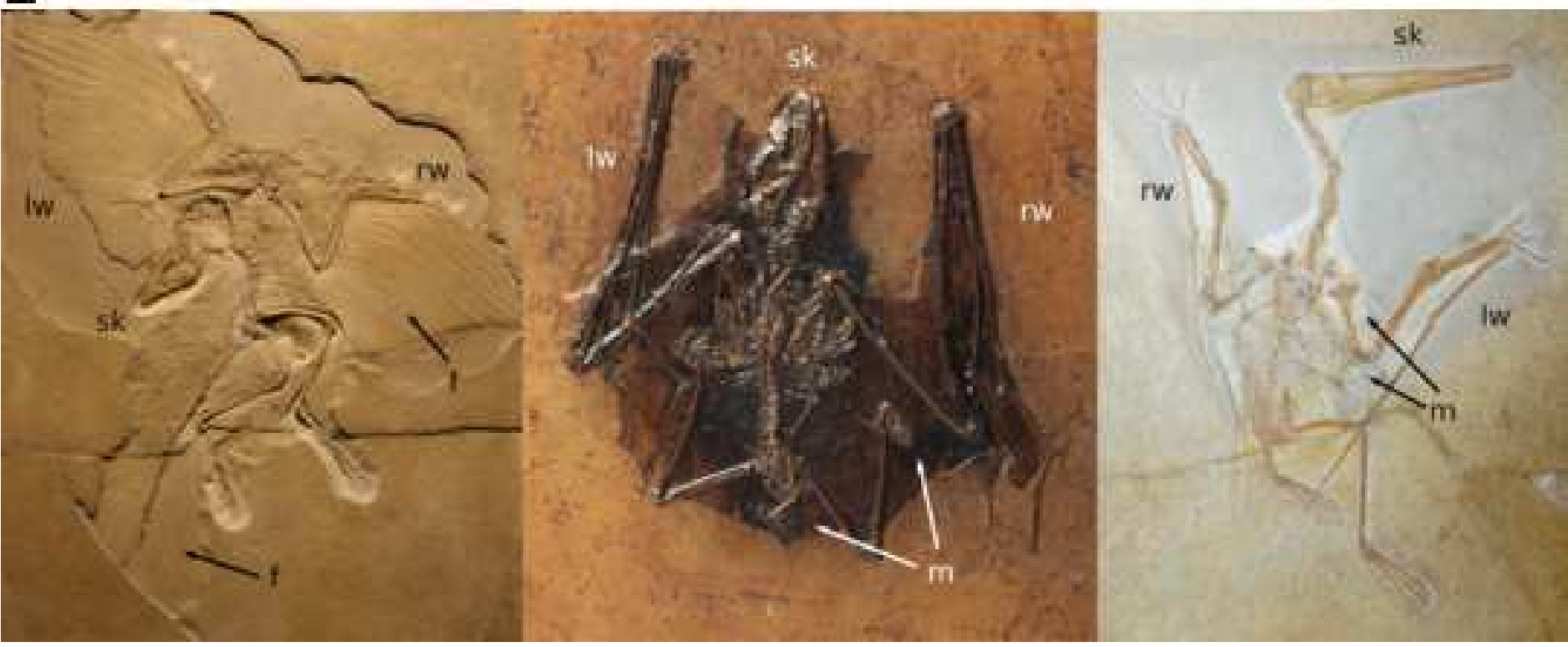
A

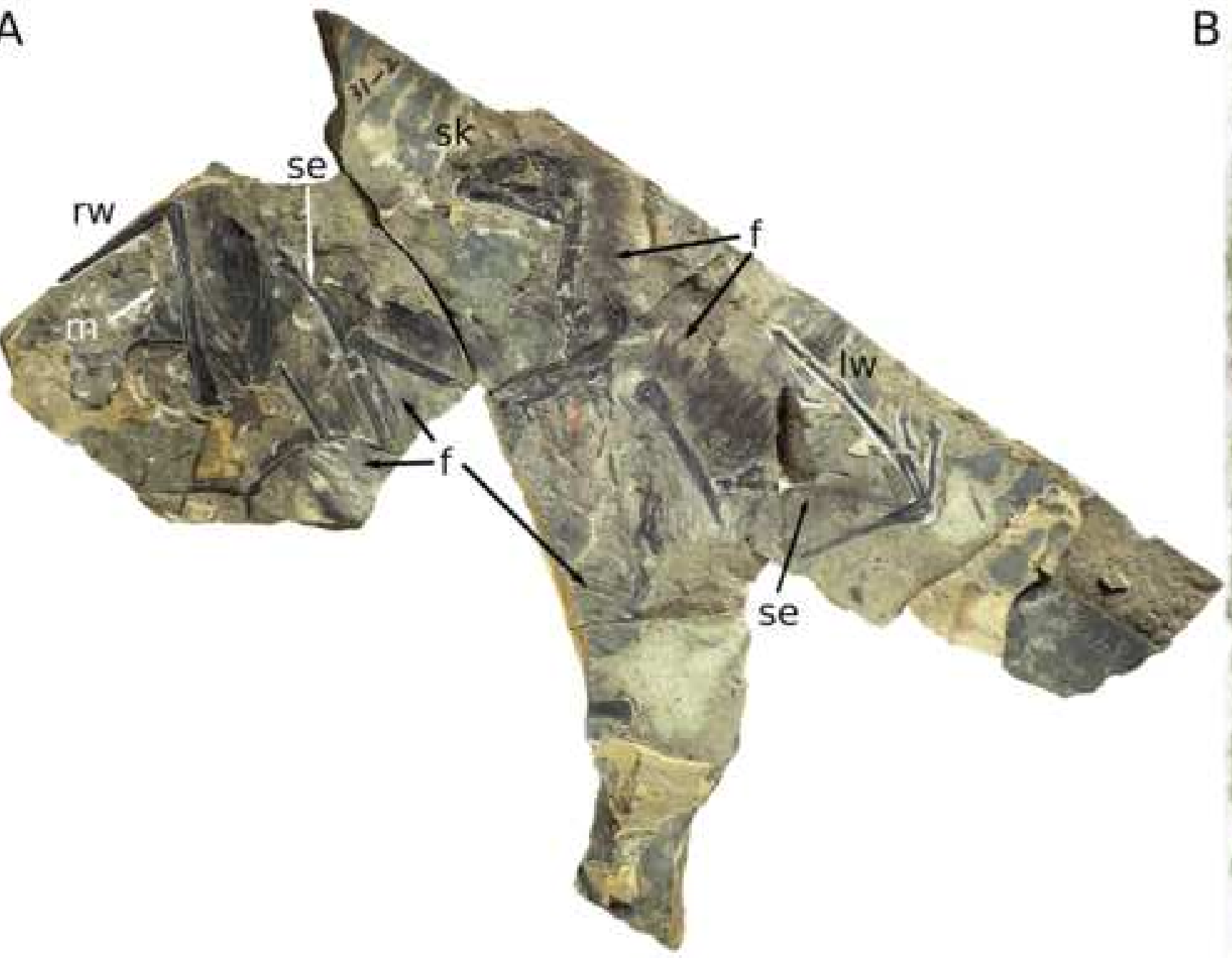

B

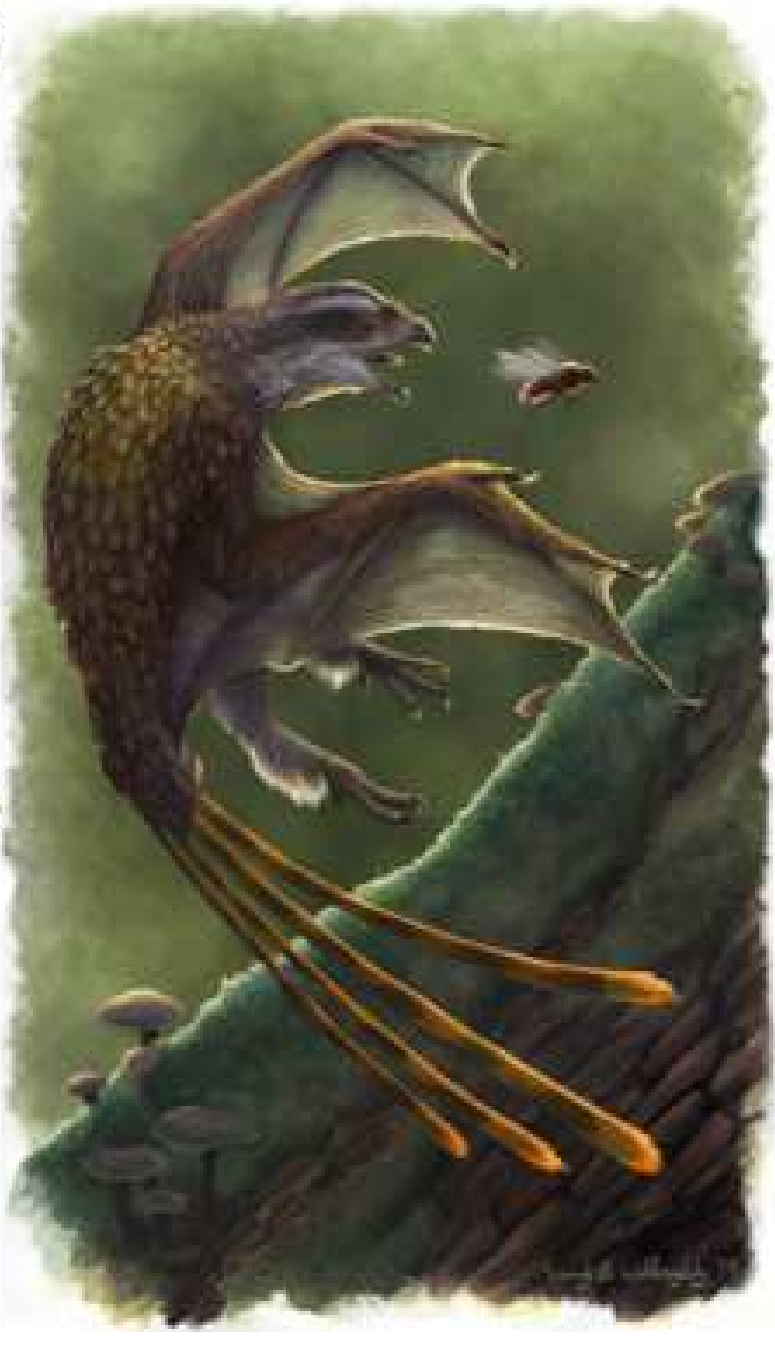




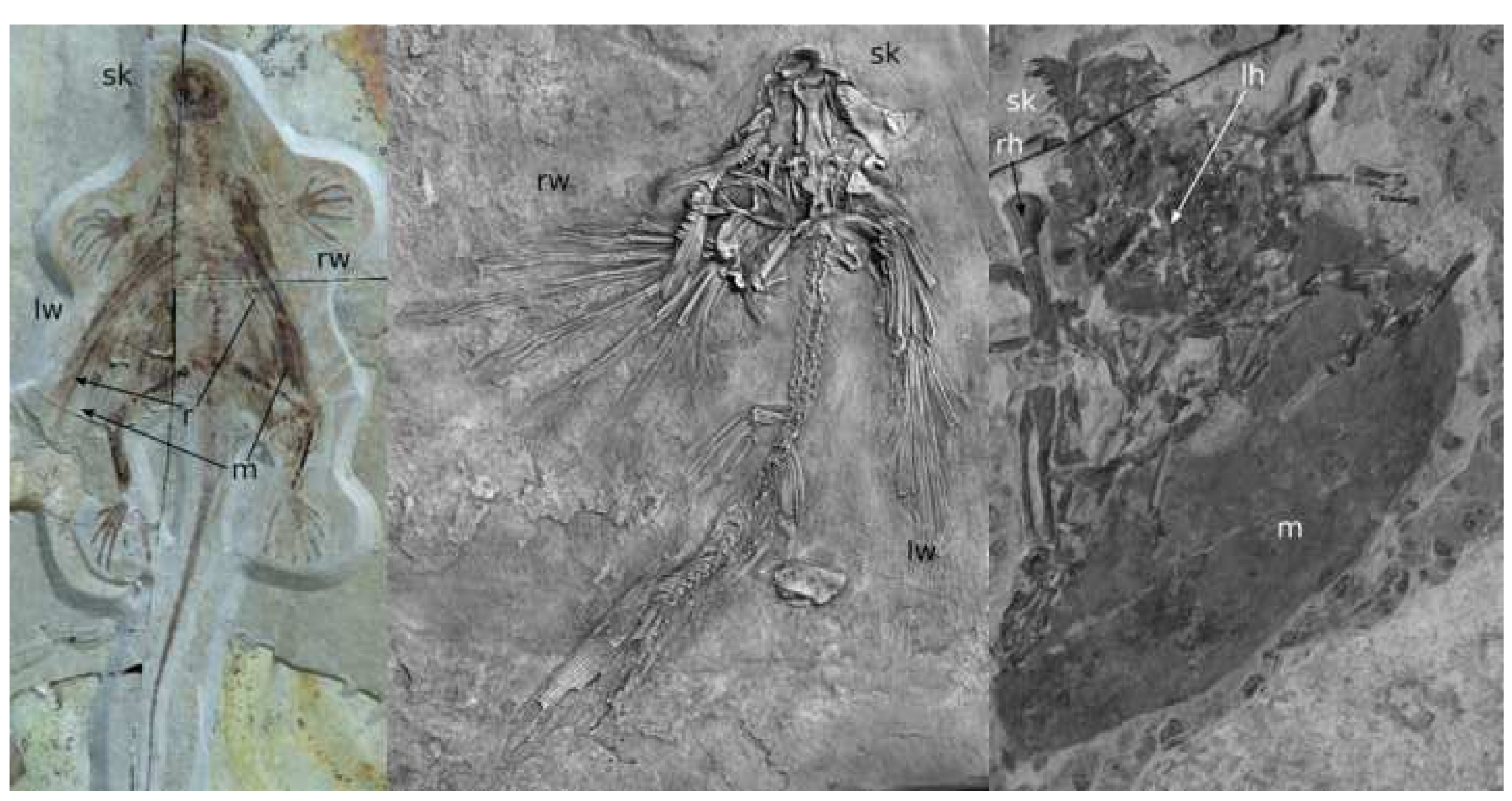



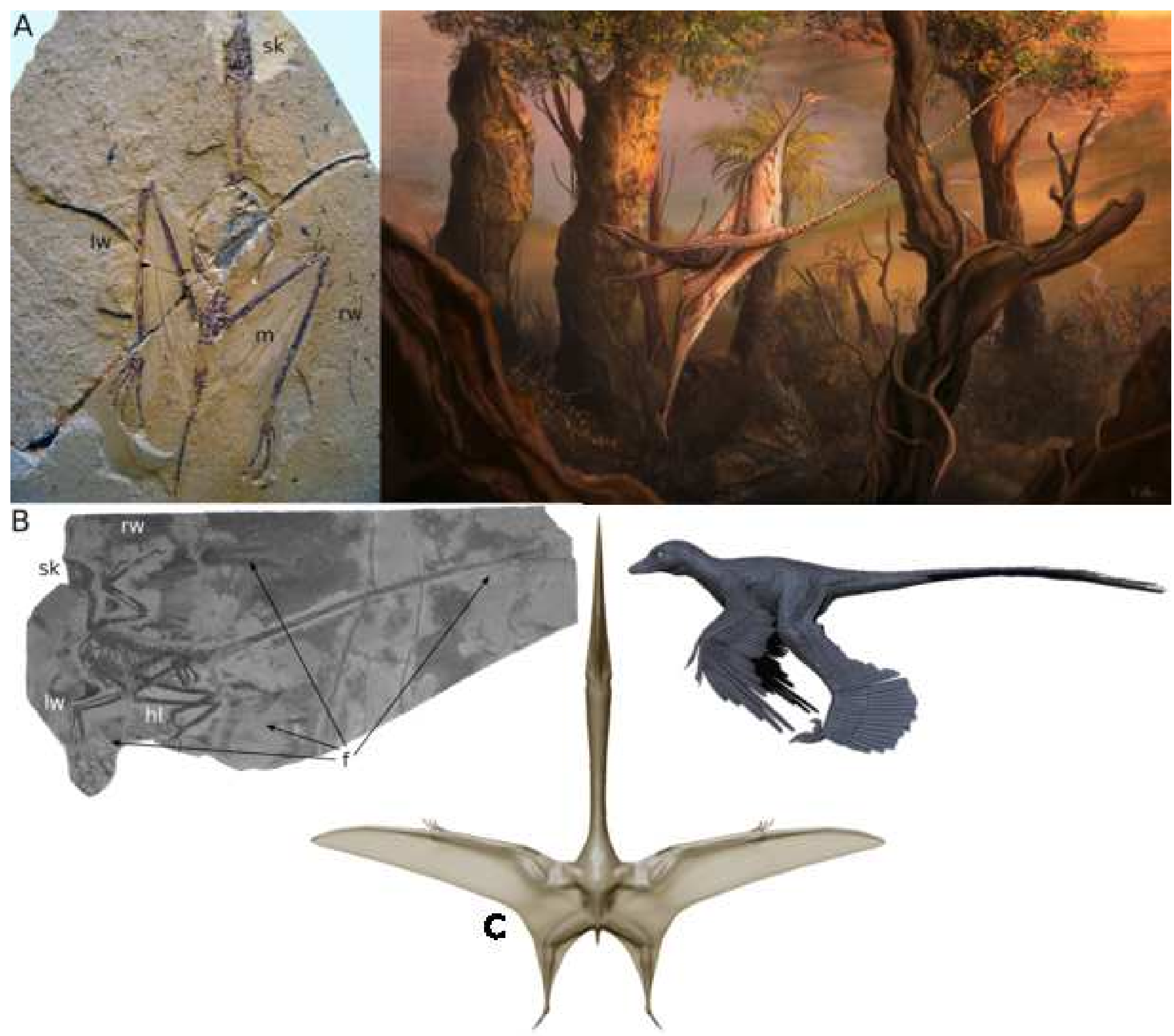
Title: Volant Fossil Vertebrates: Potential for Bioinspired Flight Technology

Authors: Elizabeth Martin-Silverstone*, Michael B Habib, David W E Hone

Authors' addresses

*Elizabeth Martin-Silverstone

School of Earth Sciences, University of Bristol, Life Sciences Building, 24 Tyndall Avenue, Bristol, BS8 1TQ, United Kingdom

Liz.martin@bristol.ac.uk

Twitter: @gimpasaura

Michael B Habib

Dinosaur Institute, Natural History Museum of Los Angeles County, 900 W Exposition Blvd, Los Angeles, CA 90007

David W E Hone

School of Biological and Chemical Sciences, Queen Mary University of London, Mile End Road, London, E1 4NS, United Kingdom

Keywords: flight, evolution, bioinspiration, biomechanics, biomimetics, fossils 


\title{
VOLANT FOSSIL VERTEBRATES: POTENTIAL FOR BIOINSPIRED FLIGHT TECHNOLOGY
}

\begin{abstract}
Animal flight is ecologically important and has a long evolutionary history. It has evolved independently in many distantly related clades of animals. Powered flight has evolved only three times in vertebrates, making it evolutionarily rare. Major recent fossil discoveries have provided key data on fossil flying vertebrates and critical insights regarding the evolution and different arrangements of animal flight surfaces. Combined with new methodologies, these discoveries have paved the way for potentially expanding biomimetic and biologically inspired designs to incorporate lessons from fossil taxa. Here, we review the latest knowledge and literature regarding flight performance in fossil vertebrates. We then synthesize key elements to provide an overview of those cases where fossil flyers might provide new insights for applied sciences.
\end{abstract}

\section{Powered flight in vertebrates}

The evolution of powered flight (see Glossary) has rarely occured in the history of vertebrate life. While there are numerous clades with members that engage in unpowered flight, powered flight has only evolved three times within vertebrate lineages, in the birds (Aves), bats (Chiroptera) and extinct pterosaurs (Pterosauria), and once in invertebrates (Insecta). Despite the rarity of powered flight as an evolved behaviour, powered flyers are common both in terms of numbers of species and individuals. Birds are the most speciose group of living terrestrial vertebrates [1] and bats are the second-most diverse clade of mammals [2]. Making an accurate species count of pterosaurs is difficult, but we can be confident that they were an important part of Mesozoic ecosystems for over 160 million years [3]. Recent reviews on birds [4], bats [5], and insects [6] have focused on studies of aerodynamics, biomechanics, and anatomical aspects of 
flight in these animals, derived from the high quality and quantity of data available from extant animals, something that is more difficult and rare in extinct taxa (e.g. pterosaurs, [7]).

The rarity of powered flight may be a result of the relatively strict requirements to generate sufficient power to overcome drag and resisting the large resultant forces (without excessive weight), while also controlling and directing movement. These physical demands require skeletons with high stiffness:weight ratios and sophisticated control surfaces [8]. Unpowered flight is more common, being known from numerous extant and extinct lineages, though it has some similar requirements [9] (Box 1). Despite constraints, each group of flying vertebrates has a fundamentally different set of anatomical "solutions" to common challenges of aerial locomotion (Fig 1).

Major fossil discoveries in recent years have provided key data on fossil flying animals. The Daohugou localities in China have produced the earliest known gliding mammal (Volaticotherium [10]) (Box 2), the oldest possible flying dinosaur (Anchiornis [11]) and new information on the structure of pterosaur wings [12]. New techniques are available to extract the available structural data and manipulate it with information from UV light [13], and surface and penetrative scanning $[14,15]$. Therefore, understanding flight in fossil forms is now considerably enhanced compared to previous years, and is set to advance further and at an increasing rate.

These new data have greatly expanded understanding of how flying animals have solved major flight challenges, including novel evolutionary solutions not seen in living species. Fundamental aspects of flight, including take-off [16,17], landing [18], the shape [19], structure [20,21] and position of control surfaces [22], glide angles [23,24], flight strokes [25], flying style [26], and active control of wings [12] are being increasingly explored in living and fossil taxa. Unique fossil-only bauplans have also been described, such as the non-avialan dinosaurs $Y i$ qi and Ambopteryx [27,28]. 
These discoveries have paved the way for the possibility of expanding biomimetic and biologically inspired design approaches to incorporate lessons from fossil taxa. A robust understanding of the origin of flight and the evolution of morphologies related to flight performance provides critical context for the constraints and optimization of biological traits that can inspire mechanical design.

\section{Wing structure and materials}

\section{Feathers}

New fossils combined with novel analyses have revealed important information on the size [29], arrangement [30], and strength [20] of the flight feathers in early birds and non-avialan dinosaurs. Integrated with new assessments of the wing positions [29], these data shed new light on the transition from gliding to powered flight. The evolution of flight-related characters, including feathers, appears to have followed a mosaic pattern, with many of the key morphologies seen in flight feathers appearing in non-flying avian relatives [31-33].

Of the key features in feathers related to sustained flight, feather vane asymmetry has been a particularly contentious topic in the past, with some (e.g. [34]) arguing that the presence of asymmetric vanes in the primary feathers of fossil birds indicates that they were powered flyers. Primary feathers with only slightly asymmetric vanes are still aeroelastically unstable [35]. A recently described troodontid dinosaur specimen further indicates that the presence of vane asymmetry may be the basal state for paravians [36]. It is therefore the evolution of more extreme vane asymmetry, rather than slight asymmetry, that was critical to avian flight.

Data on the stiffness of some fossil feather rachises indicate that the primary feathers would have been weaker in bending than comparable feathers in modern birds and suggesting that these taxa were incapable of the same flight gaits seen in modern birds [20,37]. Additional studies 
have looked at the molecular structure, genetics and bioarchitecture of feathers, suggesting that biomechanical features were present both at the morphological and molecular levels during the acquisition of flight $[38,39]$. Though it has recently been argued that bird feathers and pterosaur integumentary fibers may share an evolutionary origin [40,41], as they are not thought to have any aerodynamic role in pterosaurs, they are not considered further here.

Unlike modern birds with a single layer of primary feathers, Archaeopteryx appears to have had multiple layers. This layering may have forced a different performance profile than in modern birds [30] and it suggests an alternative system for the control of aeroelasticity that compensated for relatively symmetric primaries and comparatively thin rachises. The recently described Changyuraptor exhibited exceptionally long tail and hind limb feathers, which have been interpreted as pitch and yaw control structures respectively that would help control the speed during descent and landing [29]. Wind tunnel experiments and flight simulations of a feathered Microraptor model revealed that they would have been efficient at low-speed gliding, using all five feathered surfaces (two forewings, two hind limbs and a tail) as lifting surfaces, a distinctly different bauplan to extant birds $[24,42]$. This distributed control system made heavy use of multi-modal components: the tail, forelimbs, and hind limbs all had functions beyond flight propulsion and control. Such multi-modal systems are relevant to UAV applications where units are required to be generalists, fulfilling multiple tasks with limited human input.

\section{Membranes}

Most information on membrane wing dynamics in living systems comes from key experimental work with bats. Bats suspend their primary wing membranes across four digits, providing substantial support for tensioning via motions of the fingers. This allows their membranes to be relatively thin, yet dynamic and structurally complex. Bat wings contain muscles and elastin fibers that affect their compliance, dynamic responses to load, material properties and structural 
properties $[43,44]$. Although little work has been done on early bat flight, the shape of early bat wings indicates a flight style of undulating gliding-fluttering may be primitive, and that the tail membrane evolved early on as an additional airfoil [26].

Within pterosaurs, understanding of the structure and arrangement of the fibers in the membraneous wings $[12,45]$, a new model for the response to the wing under loading [21], and the position of the wings in steady flight [46] combine to give a much revised and enhanced picture of pterosaur flight capacity. Pterosaur flight membranes consisted of at least three distinct tissue layers with actinofibrils throughout $[12,45]$. These likely functioned in a structural manner by increasing the tensile strength and flexibility of the membrane [47] although their exact function is difficult to determine without knowing their composition $[12,45,46]$. Estimates of membrane tension in pterosaur wings, derived from aeroelastic limits and wing bone stiffness, suggest that these actinofibrils must have been keratinous to reinforce the membrane, significantly differing from the membranes of bats [48]. All fossils that have relevant portions preserved and undistorted show the membrane attaching to the lower leg or ankle [49].

Wind tunnel tests indicate that the pterosaur wing was likely adapted to generate and operate at relatively high lift coefficients [46]. As a result, pterosaurs were probably not well adapted to fly at high speeds but were instead efficient at low speed flight. This would have provided significant advantages during thermal soaring and allowed low-speed landings [46]. These factors also lower the energy requirements for launch at large body sizes. Optimization for slow, highly manoeuvrable flight is relevant to urban performance UAV markets (both commercial and military), where the environments are often highly cluttered and target surfaces for landing may be very small. As such, animals adapted to fly at high lift coefficients, both living and fossil, might have a great deal to offer engineers in terms of shape and material optimization. 
Mechanical considerations indicate that pterosaur wings must have had a concave posterior margin to avoid aeroelastic instability. Proper tensioning of membrane wings in pterosaurs would have been impossible with a convex posterior margin, because of the single-spar construction [50]. A theoretically most efficient wing shape would combine a lunate wingtip (supported by both soft tissue preservation [49] and osteology [21]) with anterior sweep to minimize induced drag and provide passive static stability [50]. It has been suggested that the largest pterosaurs were secondarily flightless (e.g. [51]), but more recent work suggests that the maximum launch-capable body mass for pterosaurs may have been quite high, owing to the high maximum lift coefficient of their wings and their potential for quadrupedal launch. Anatomical evidence combined with mechanical constraints suggests that the largest known pterosaurs, with wingspans of over 10 meters, were still not at a mechanical limit for launch and flight $[17,52,53]$. Detailed biomechanical studies comparing the largest pterosaurs with birds show that flying is easily possible and not limited until wingspans upwards of $15 \mathrm{~m}$, at the low flight speed predicted for pterosaurs [46,53]. It is actually launch that limits the maximum size of pterosaurs, and assuming a quadrupedal launch, this would be possible to approximately $12 \mathrm{~m}$ wingspans [53]. This is possible due to the large pectoral and flight musculature present in pterosaurs, making up approximately $40 \%$ of their total body mass $[54,55]$.

Pterosaurs possessed a respiratory system made up of a series of pulmonary air sacs, both in the main body cavity and subcutaneous air sacs in the wings of some [56] which may have influenced the cross-sectional of the wings and by extension wing performance. This results in wing bones frequently being hollow but not necessarily lighter than equivalent apneumatized bones [57]. Some large pterosaur wing bones are among the most pneumatic bones ever found, with perhaps $90 \%$ of the bone volume being filled with air [58]. These thin-walled pneumatic wing bones become more resistant to bending as the diameter of the bone increases, an important feature as the animal's mass increases and bending loads on the wings get larger [58]. However, 
additional data indicate that the wing bones of pterosaurs may not have been as light as previously thought, leading to new questions about mass estimation in pterosaurs [59].

\section{Challenges of flight}

The evolution of powered flight in animals ultimately includes three major components: the evolution of launch, the origin of a thrust-producing flight stroke, and the evolution of in-flight control. These characteristics are all interrelated and presumably evolved partly in parallel, but likely appeared somewhat piecemeal.

\section{Launch and Landing}

Launch and landing are critical phases of flight and are likely the limiting factors on maximum size for flying animals. The use of the walking limbs to initiate launch from a level surface is ubiquitous in flying animals. In small birds such as hummingbirds (Trochilidae), about 50\% of the launch force is derived from the legs [60] and for other birds often $80-90 \%$ of the launch is from leaping or running [61]. Some bats launch from the ground using quadrupedal leaping $[62,63]$. Ballistic launch is also fundamental to unpowered flyers - gliding mammals take off by leaping [64], and gliding snakes are the only snakes that can truly jump in the biomechanical sense [65], highlighting the importance of leaping for animal flight. Based on bone crosssectional properties, trackways, and comparisons with modern taxa, it has been hypothesized that many (if not most) pterosaurs probably also launched in a semi-ballistic fashion via quadrupedal leaping $[17,52]$. The use of a quadrupedal launch was likely an important factor that allowed for giant size in pterosaurs $[17,52,53]$. Their membrane wings also contributed to a higher maximum size limit by providing much higher maximum lift coefficients than the comparatively thick wings of birds. While the largest flying birds probably massed around $75 \mathrm{~kg}$, the largest 
pterosaurs likely massed nearly $300 \mathrm{~kg}[51,66]$. This difference highlights the substantially greater power:mass ratio during launch for a quadrupedal launcher compared with a bipedal launcher.

\section{Optimizing wing performance}

Flying vertebrates can optimize their wing performance to changing conditions by changing their wing shape in flight. In terms of morphing wing capacity, flying animals significantly outperform existing manufactured systems. Ratios of Lift to Drag (L:D) are important to soaring flight, as this sets the minimum glide angle. Birds, in particular, have significant morphing wing strategies to achieve improved L:D ratios while soaring. The effective aspect ratios of the wings of inland soaring birds (e.g. Harris's hawks) are higher than the anatomical values usually reported in the literature, because the use of tip slots increases the effective aspect ratio at low speeds $[67,68]$. As the wings of flying animals are not fixed, they can adjust the relative angle of sweep of the wings over a continuous range of positions to stabilize themselves in pitch. For those with compliant wings, an inboard reflex camber might also be a method of achieving pitch stability. Reflex camber occurs when the curvature of the wing reverses in part of the wing, forming an area where the upper surface of the wing is slightly concave, instead of the lower surface being concave. For the "inboard" case, this means that the part of the wing closest to the body is the section that is "flipped". This requires a compliant, morphing wing with complex control. Pterosaurs, in particular, seem to have had morphological traits that would enable them to utilize an inboard reflex camber, likely in conjunction with forward wing sweep [50]. These advantages and constraints have implications for both morphing wing designs in air vehicles and reconstructions of fossil taxa.

\section{Control}


Flight stability in animals has been achieved differently, in some respects, to that of most fixedwing aircraft. It is notable, for instance, that no living flying animals possess a vertical tail wing as utilized by modern traditional aircraft and vertical tails are almost unknown in the fossil record as well. Microraptorines possessed a pair of vertical wings on the hind limbs, but these were not placed nor shaped like the tail rigs on aircraft (and may have been dynamic control surfaces for turning, rather than stabilizing) [24,42]. Similarly, bats use the positioning of their tail membrane (uropatagium) to control the angle of attack and pitch [69].

The tail fan of living birds is a dynamic structure with the capacity to affect dynamic control of yaw, pitch, and roll although the tail is not necessary for flight control in birds. The tail fans of microraptorines emerged at the distal end of typically dinosaurian long, bony tail and may have been more specialised to pure pitch control [29], though the mass of the tail compared to birds may have provided counterbalancing functions. This multi-modality can provide a useful model for UAV systems that are also built to climb or cling to walls.

Regarding tails, it may be the fact that flying animals do not need vertical tails that may be of the most interest to engineers. Flying animals appear to make use of spanwise twist in the wing, thereby shedding the outboard ("tip") vortices slightly inboard (proximal) of the wing tip. This results in proverse yaw while turning, instead of adverse yaw [70]. As a result, animals do not require vertical tails or rudder-type elements for flight control. Such vertical tail rigs in fixed wing aircraft are quite costly. Utilizing lift distributions more akin to those of flying animals could provide exceptional efficiency gains [70]. While living animals will inevitably provide much of the data for this application, each group of vertebrate flyers has achieved the required span-wise twist slightly differently. The pterosaur solutions to this problem are only decipherable from the fossil record, however, since they have no living representatives. Furthermore, 
pterosaurs appear to have been exceptionally effective at controlling yaw and pitch, often with hardly any tail system at all. So much so, in fact, that many species could afford enormously expanded heads and/or massive cranial ornamentation.

\section{Future directions in Biology}

Early forms of flying animals were likely small, rare, with some level of reduced skeletal mass, and in inland arboreal environments - all major biases against producing fossils. As a result, the discovery of many intermediate forms in the origin of flight may be near fruitless. Many extinct flying lineages are known only from species that were fully flight capable with no early forms showing limited, or even lacking, flight $[3,26]$. However, future discoveries may fill these gaps, and further studies of the flight of early forms may constrain the possible macroevolutionary pathways (e.g. [71]).

In contrast to bats and pterosaurs, there is an extensive bird fossil record with numerous forms that had varying degrees of inferred flight capability [11,31,32]. As a result, the origin and evolution of feathers prior to the origin of flight are now known in detail $[41,72,73]$. There remains controversy over the origins of bird flight. Prior positions have often been one of a 'ground-up' progression to flapping flight from terrestrial ancestors, or a 'trees-down' from gliding, arboreal ancestors (although any animal that had reached the ground through gliding would need to gain height again and some form of flapping-climbing would integrate both hypotheses) $[74,75]$. Resolving these competing ideas is generating an ever better understanding of the functional anatomy of these animals (e.g. [25]) (Outstanding Questions).

\section{Future Directions in Engineering and Technology}

This new and enhanced level of understanding of flight in fossil animals is well timed to integrate with a major area of engineering - that of human constructed vehicles (Box 3). 
Increasingly engineers are turning to living organisms for inspiration of known evolutionary 'solutions' to mechanical problems. In the case of flight, engineers already look to extant birds, bats, and insects (though it is a young field) [76], but this overlooks the huge diversity of fossil forms and their different anatomical arrangements (Fig 2). Microraptor has been suggested as an option for fossil-inspired biomimicry [77], and pterosaurs have been briefly suggested as models [78] though neither has been investigated in detail.

Potential for future technology: Fossil forms provide a plethora of structures and integrated systems that can contribute to next-generation aircraft, robots, low-flutter fabrics, and ultra-light structures.

1. Novel methods for achieving aeroelastic stability. Inspiration: pterosaurs. Industry engineers have already begun to integrate information from palaeontologists into their models and consideration of biomimetic structures. Lockheed Martin - a global aerospace company- is including paleontological data in their training series. We note that pterosaur-based wing designs may be particularly good at controlling aeroelastic flutter. Engineering colleagues of the authors have already noted this feature in personal communications (G. Spedding, C. Palmer, J. Cunningham, pers. comms.). Pterosaurs are a particularly useful model for investigating aeroelastic control, because their single spar wing structure made aeroelastic control particularly critical to their flight performance. The specifics of actinofibril orientation, tissue layering, wing shape, and span-wise bone geometry in the wing were all involved in utilizing and controlling aeroelasticity in the wings of pterosaurs.

\section{Development of morphing wings. Inspiration: all flying vertebrates. Biologically} inspired, compliant-wing ornithopters [76] also utilize the single-spar wing concept observed in pterosaurs, integrated with anatomical features of other flying animals. 
Future biological inspired designs will likely continue to be integrative, combining both fossil and extant animal features with traditional design concepts in mechanical engineering (such as adding pterosaur inspired control features to otherwise traditional aircraft - see [79]).

3. Utilizing Gaussian lift distributions. Inspiration: all flying vertebrates. The spanwise twist solution to adverse yaw used by flying animals eliminates their need for a vertical, yaw-correcting tail. Such tails are aerodynamically costly as they result in adverse lift and significant additional drag. Furthermore, alleviating the need for a standard vertical tail rig provides opportunities to design alternative tail rigs (if desired) that provide performance gains. Recent NASA experiments recovered up to $24 \%$ efficiency gains by using biomimetic wings based on this principle [70].

4. Self-launching and landing robots. Inspiration: multi-modality from birds, powerful ground launch from pterosaurs, and ceiling launching from bats. Flying animals excel at sudden take-off, landing on uneven terrain, and quickly/completely storing wings before and after flight. Mechanical designs currently perform much more poorly than animals these tasks. Biologically solutions may be a key guide to future improvements in UAV launch, landing, and storage. Pterosaur launch models may be particularly informative in this regard, as their takeoff system was effective over a very wide range of body sizes. With body masses ranging from a few tens of grams to well over $200 \mathrm{~kg}$ (and possibly over $300 \mathrm{~kg}$ ), pterosaurs overlapped much of the size range relevant to modern drones (The LaFlamme Aero Inc LX300, among the larger helicopter type drones, has a maximum takeoff mass of $300 \mathrm{~kg}$, for example).

5. Unconventional control surfaces. Inspiration: microraptorines, pterosaurs. Winged, non-avian dinosaurs used an arrangement of four wings (with the set on the hind limbs 
likely being a vertical set that acted mostly in yaw and roll) as well as control from the tail [29], while pterosaurs have a biologically unique wing with a bony spar at the leading edge and a complex multi-layered membrane behind $[12,45,46,48]$ and a tail vane. As pterosaurs were the largest animals to fly, this is also a biologically successful morphology that provides useful insights for engineering questions $[53,54]$.

6. Hybrid wings. Inspiration: Yi qi and Ambopteryx. These are the only feathered animals known with extensive membrane wings (Fig 2). A new array of biomimetic options is opened by the prospect of creating wings through a combination of compliant surfaces with stiff, sliding surfaces. Applications of these fundamentals will be an exciting challenge for engineers. Biologists will have opportunities to use evolutionary theory and fossil records to help explain the conditions under which a wing like that of $Y i$ qi and Ambopteryx may have evolved.

\section{Concluding remarks: Why use information from fossils to improve technology?}

Assessments of the flight performance of fossils forms have unique problems as specimens are often incomplete or not preserved in three dimensions. However, rising to the challenge of creating robust models of performance for fossil species yields unique insights and pushes the limits of flight research in fundamentally productive ways. Furthermore, the sheer diversity of form and phylogeny covered by fossil taxa (far beyond the small fraction of life currently extant) provides exciting and unique opportunities for expanding our understanding of biology and mechanics. It is possible to extract considerable information from extinct animals and the integration and synthesis of the fields of palaeontology, biomechanics and aeronautical engineering has enormous potential to generate new and critical knowledge to the understanding of each area, see Outstanding Questions. 


\section{Box 1 - Types of flight}

Dozens of different lineages of vertebrates (extant and extinct) have evolved various ways of moving through the air with varying abilities. Biomechanists have defined multiple forms of flight in animals.

'Parachuting' is typically used for those animals that are passive fliers (i.e. are not flapping) that descend at an angle of greater than $45^{\circ}$ (i.e. they lose one or more units of height for each unit of horizontal length travelled [8]). Many animals have limited flight capability and may be engaged in little more than a controlled fall of slightly reduced speed (e.g. some squirrels [80]; frogs [81]; and geckos [82]).

'Gliding' is used for animals covering greater distances and descend at an angle less than $45^{\circ}$. This passive mode of flight is very common and includes species with considerably smaller glide angles (less sink relative to forward travel) than might be expected including snakes [65] and various primates [83] in addition to more 'traditional' gliders such as the lizard Draco, colugos (Dermoptera) and marsupial sugar gliders (Petaurus breviceps).

Soaring is a form of passive flight (though as with gliding, is often a behaviour of powered fliers) which involves using external sources of lift. Soaring flight extracts energy from the movement of air to gain altitude or speed. Soaring most often involves the use of thermals (e.g. vultures, Accipitridae, Cathartidae) or the action of wind gradients (e.g. albatross, Diomedeidae), which are used to gain height and glide to a new location making this a very efficient form of travel.

Powered flight relates to those animals engaged in flapping flight that can increase their height in still air. The only known vertebrate clades to have evolved powered flight are the birds (Aves), bats (Chiroptera) and the extinct pterosaurs (Pterosauria). All three are highly diverse and longlived clades. 
Hovering relates to animals being able to remain at one point in the air. This may be achieved through powered flight in still air (e.g. hummingbirds, Trochilidae) or passively with air moving over the wings (e.g. kestrels, Falco).

Other forms of locomotion are known such as flying fish that do not flap their 'wings' (the pectoral fins) but use them to passively generate lift while the tail paddles in the water to generate thrust. Powered fliers may exhibit different gaits with varied patterns and style of wingbeats.

\section{Box 2 - Vertebrate fliers in the fossil record}

The fossil record contains numerous taxa that are relatives of extant fliers (fossil birds and bats, but also for example flying fish [84]) but also those that apparently had converged on near identical planforms with modern taxa (Fig I, Fig II). The small gliding lizard Draco uses a flap of skin supported by extended ribs to glide, but this planform is also known from a separate lineage of Triassic reptiles including Icarosaurus [85], and a Jurassic gliding mammal, Volaticotherium is known from China [10] which flew with a membrane very similar to that employed by various extant mammals including flying squirrels (Pteromyini) and marsupial sugar gliders.

However, other forms appear in the fossil record that are quite unknown among extant animals. The small Triassic reptile Sharovipteryx (Fig IIA) was apparently a glider that had extensive membranes between its long legs forming a delta-wing, greatly reduced arms, but a small set of anterior canards supported by the hyoids [86].

Non-avialan dinosaurs also provide additional planforms. Various small, feathered dinosaurs that were close to the origin of birds included forms that apparently could parachute or glide based on 
wings on the forelimbs and hindlimbs which produced a combination of lifting and steering surfaces, bolstered by a broad flap of feathers on the tail (Microraptor [24,42] (Fig IIB), Anchiornis [11]). Finally, the recently discovered $Y i$ and Ambopteryx show a melange of features - notably an enlarged wrist bone supporting an apparently small membranous wing, but also a flight surface composed of feathers [27,28] (Fig. 2).

Finally, the Mesozoic pterosaurs were powered fliers that had a complex and multi-layered membranous wing supported by a single spar (the arm and an elongated fourth finger). Additional smaller membranes to the fore and rear assisted with control. The largest pterosaurs reached in excess of $10 \mathrm{~m}$ in wingspan, $250 \mathrm{~kg}$ and had skulls perhaps $3 \mathrm{~m}$ long, vastly exceeding any other known flying animal in size and weight (Fig IIC) [3].

Although some limited attempts have been made to build vehicles based on pterosaurs, they remain an overlooked model for flying machines, and the other taxa provide additional novel planforms which may be exploited. Yi and Ambopteryx in particular show that truly novel and, importantly, unpredicted, combinations of flying features can still be discovered.

\section{Box 3: Key areas mechanically}

There are a number of anatomic and functional aspects of extinct organisms that can potentially be used to improve the design of existing aircraft or form the basis of future ones. The folding, multifunctional, single spar, and membranous wing of pterosaurs provides an excellent model for a multi-modal wing concept that has significant morphing capacity. Such wings scaled effectively, as well: flying juveniles of the smallest pterosaurs were the size of songbirds, while the largest adults had wingspans in excess of 10 meters. The combination of multiple spars supporting both a membrane and feathers, as in $Y i$ (Fig 2), provides a model for combining 
relatively stiff wing sections with highly compliant ones, all integrated such that the wing was still foldable. Such wings can function in a fixed position but can also change shape and performance to respond to varying conditions, alleviate loads from gusts, or to fold into a terrestrial support position. Similarly, the shape, position and construction of control surfaces used by pterosaurs or Sharovipteryx provide examples of successful compliant control surfaces. Compliant surfaces are inherently dynamic and can produce high lift coefficients, traits of importance for designs intended to carry heavy loads or work in unpredictable environments.

The construction of the wing, such as the multiple layers of stiffening fibers combined with muscle fibers (e.g. something which can change the shape and camber of the wing) in pterosaurs provide additional means to alter wings, or even sections of wing, during flight to improve control or performance. The formation of a high-performance structure using composites of comparatively simple subunits is a common theme in animal morphology, and it is particularly true of animal wings. Thanks to high-fidelity preservation of pterosaurs from Brazil, China, and Germany, it is possible to examine these composite morphologies even in fossil flyers.

Wake modulation is a common feature of living flyers, and it appears to have been important for extinct flyers, as well. Fibers of various types are seen on the bodies of flying animals (both powered and unpowered) which can help create a well-connected boundary layer and reduce drag. Some pterosaurs show fibers on the wing analogous to those feathers of owls that reduce sound [3].

\section{Outstanding questions}

How does the evolution of control fit into the scheme of biological flight? Future work needs to examine whole animals, especially control elements beyond the main wings (e.g. nonpterodactyloid pterosaur tails, dromaeosaur tails). 
How does the evolution of powered and unpowered flight compare? Work has historically focused on powered flight, but obligate gliders also utilize dynamics of interest. Of interest here will be tests of the hypothesis that an obligate glider stage is an intermediate in the evolution of powered flight. To date, this is a highly contentious concept.

\section{How do flying vertebrates balance the requirements of powered flight against other} developmental, ecological, and morphological constraints? All flyers maintain feeding structures, reproductive structures, and a basic body plan set by strict developmental constraints. Despite the trade-offs of aerial locomotion, some flying animals also balance(d) extreme morphologies unrelated to flight. For example, many pterosaurs had enormously enlarged heads and/or necks, which would have demanded novel wing positions and/or body density distributions to solve problems of pitch.

How do flying animals transition between the air and other substrates? Beyond sustained aerial locomotion, take-off and landing are also critical components of flight and have rarely been studied. There is much to learn about launch mechanics, landing dynamics, and wing folding/unfolding. These are highly likely to yield new insights applicable to engineering and mechanical design, because sudden takeoff, landing on uneven surfaces, and complex wing folding are areas where animals excel but human designs are still relatively basic.

What are the mechanical properties of animal wings, and can we estimate these properties for fossil taxa? Few projects have quantitatively estimated the wing material properties in fossil vertebrates. Understanding how high performance biological materials evolved will provide important biomechanical context in extant species. 


\section{References}

1 Burleigh, J.G. et al. (2015) Building the avian tree of life using a large-scale, sparse supermatrix. Mol. Phylogenet. Evol. 84, 53-63

2 Jones, K.E. et al. (2002) A phylogenetic supertree of the bats (Mammalia: Chiroptera). Biol. Rev. Camb. Philos. Soc. 77, S1464793101005899

3 Witton, M.P. (2013) Pterosaurs: natural history, evolution, anatomy, Princeton University Press.

4 Altshuler, D.L. et al. (2015) The biophysics of bird flight: functional relationships integrate aerodynamics, morphology, kinematics, muscles, and sensors. Can. J. Zool. 93, 961-975

5 Swartz, S.M. and Konow, N. (2015) Advances in the study of bat flight: the wing and the wind. Can. J. Zool. 93, 977-990

6 Hedrick, T.L. et al. (2015) Recent developments in the study of insect flight 1. Can. J. Zool. 93, 925-943

7 Middleton, K.M. and English, L.T. (2015) Challenges and advances in the study of pterosaur flight. Can. J. Zool. 93, 945-959

8 Rayner, J.M. V (1981) Flight adaptations in vertebrates. Symp. Zool. Soc. London 48, $137-172$

9 Norberg, U.M. (1985) Evolution of Vertebrate Flight: An Aerodynamic Model for the Transition from Gliding to Active Flight. Am. Nat. 126, 303-327

10 Meng, J. et al. (2006) A Mesozoic gliding mammal from northeastern China. Nature 444, 889-893

11 Xu, X. et al. (2009) A new feathered maniraptoran dinosaur fossil that fills a morphological gap in avian origin. Sci. Bull. 54, 430-435

12 Kellner, A.W.A. et al. (2010) The soft tissue of Jeholopterus (Pterosauria, Anurognathidae, Batrachognathinae) and the structure of the pterosaur wing membrane. Proc. R. Soc. B Biol. Sci. 277, 321-329

13 Hone, D.W.E. et al. (2010) The Extent of the Preserved Feathers on the Four-Winged Dinosaur Microraptor gui under Ultraviolet Light. PLoS One 5, e9223

14 Bergmann, U. et al. (2010) Archaeopteryx feathers and bone chemistry fully revealed via synchrotron imaging. Proc. Natl. Acad. Sci. U. S. A. 107, 9060-5

15 Koehl, M.A.R. et al. (2011) Using Physical Models to Study the Gliding Performance of Extinct Animals. Integr. Comp. Biol. 51, 1002-1018

16 Burgers, P. and Chiappe, L.M. (1999) The wing of Archaeopteryx as a primary thrust generator. Nature 399, 60-62

17 Habib, M.B. (2008) Comparative evidence for quadrupedal launch in pterosaurs.

Zitteliana B 28, 159-166 
18 Walker, A.D. (1977) Evolution of the pelvis in birds and dinosaurs. In Problems in Vertebrate Evolution (Andrews, S. M. et al., eds), pp. 319-357, Linnaean Society

19 Li, Q. et al. (2012) Reconstruction of Microraptor and the Evolution of Iridescent Plumage. Science (80-. ). 335, 1215-1219

20 Nudds, R.L. and Dyke, G.J. (2010) Narrow Primary Feather Rachises in Confuciusornis and Archaeopteryx Suggest Poor Flight Ability. Science (80-. ). 328, 887-889

21 Hone, D.W.E. et al. (2015) The wingtips of the pterosaurs: Anatomy, aeronautical function and ecological implications. Palaeogeogr. Palaeoclimatol. Palaeoecol. 440, 431-439

22 Elgin, R.A. et al. (2008) Aerodynamic characters of the cranial crest in Pteranodon. Zitteliana B28, 167-174

23 Stein, K. et al. (2008) The aerodynamics of the British Late Triassic Kuehneosauridae. Palaeontology 51, 967-981

24 Dyke, G. et al. (2013) Aerodynamic performance of the feathered dinosaur Microraptor and the evolution of feathered flight. Nat. Commun. 4, 2489

25 Dial, K.P. et al. (2008) A fundamental avian wing-stroke provides a new perspective on the evolution of flight. Nature 451, 985-989

26 Simmons, N.B. et al. (2008) Primitive Early Eocene bat from Wyoming and the evolution of flight and echolocation. Nature 451, 818-821

$27 \mathrm{Xu}$, X. et al. (2015) A bizarre Jurassic maniraptoran theropod with preserved evidence of membranous wings. Nature 521, 70-73

28 Wang, M. et al. (2019) A new Jurassic scansoriopterygid and the loss of membranous wings in theropod dinosaurs. Nature 569, 256-259

29 Han, G. et al. (2014) A new raptorial dinosaur with exceptionally long feathering provides insights into dromaeosaurid flight performance. Nat. Commun. 5, 4382

30 Longrich, N.R. et al. (2012) Primitive Wing Feather Arrangement in Archaeopteryx lithographica and Anchiornis huxleyi. Curr. Biol. 22, 2262-2267

$31 \mathrm{Xu}, \mathrm{X}$. et al. (2014) An integrative approach to understanding bird origins. Science 346, $1253293-1253293$

32 Brusatte, S.L. et al. (2015) The Origin and Diversification of Birds. Curr. Biol. 25, R888R898

33 Brusatte, S.L. (2017) A Mesozoic Aviary. Science 355, 792-794

34 Feduccia, A. (1999) The Origin and Evlution of Birds, Yale University Press.

35 Feo, T.J. et al. (2015) Barb geometry of asymmetrical feathers reveals a transitional morphology in the evolution of avian flight. Proc. R. Soc. B Biol. Sci. 282, 2014286420142864

$36 \mathrm{Xu}, \mathrm{X}$. et al. (2017) Mosaic evolution in an asymmetrically feathered troodontid dinosaur 
with transitional features. Nat. Commun. 8, 14972

37 Wang, X. et al. (2012) Size scaling and stiffness of avian primary feathers: implications for the flight of Mesozoic birds. J. Evol. Biol. 25, 547-555

38 Pan, Y. et al. (2019) The molecular evolution of feathers with direct evidence from fossils. Proc. Natl. Acad. Sci. U. S. A. 116, 3018-3023

39 Chang, W.-L. et al. (2019) The Making of a Flight Feather: Bio-architectural Principles and Adaptation. Cell 179, 1409-1423.e17

40 Yang, Z. et al. (2019) Pterosaur integumentary structures with complex feather-like branching. Nat. Ecol. Evol. 3, 24-30

41 Benton, M.J. et al. (2019) The Early Origin of Feathers. Trends Ecol. Evol. 34, 856-869

42 Evangelista, D. et al. (2014) Aerodynamic Characteristics of a Feathered Dinosaur Measured Using Physical Models. Effects of Form on Static Stability and Control Effectiveness. PLoS One 9, e85203

43 Cheney, J.A. et al. (2014) Membrane muscle function in the compliant wings of bats. Bioinspir. Biomim. 9, 025007

44 Cheney, J.A. et al. (2015) A wrinkle in flight: the role of elastin fibres in the mechanical behaviour of bat wing membranes. J. R. Soc. Interface 12, 20141286-20141286

45 Frey, E. et al. (2003) New specimens of Pterosauria (Reptilia) with soft parts with implications for pterosaurian anatomy and locomotion. In Evolution and Palaeobiology of Pterosaurs 217 (Buffetaut, E. and Mazin, J.-M., eds), pp. 233-266, Geological Society of London Special Publications

46 Palmer, C. (2011) Flight in slow motion: aerodynamics of the pterosaur wing. Proc. $R$. Soc. London B Biol. Sci. 278, 1881-1885

47 Bennett, S.C. (2000) Pterosaur flight: the role of actinofibrils in wing function. Hist. Biol. $14,255-284$

48 Palmer, C. (2017) Inferring the properties of the pterosaur wing membrane. In New Perspectives on Pterosaur Palaeobiology 455 (Hone, D. W. E. et al., eds), Geological Society of London Special Publications

49 Elgin, R.A. et al. (2011) The extent of the pterosaur flight membrane. Acta Palaeontol. Pol. 56, 99-111

50 Palmer, C. and Dyke, G. (2012) Constraints on the wing morphology of pterosaurs. Proc. R. Soc. B Biol. Sci. 279, 1218-1224

51 Henderson, D.M. (2010) Pterosaur body mass estimates from three-dimensional mathematical slicing. J. Vertebr. Paleontol. 30, 768-785

52 Witton, M.P. and Habib, M.B. (2010) On the size and flight diversity of giant pterosaurs, the use of birds as pterosaur analogues and comments on pterosaur flightlessness. PLoS One 5, e13982

53 Palmer, C. (2016) Flexible fliers: the flight of pterosaurs. University of Bristol, PhD 
Thesis. Available at http://colinpalmer.eu/pterowing/phd/

54 Strang, K.A. et al. (2009) Efficient flight of pterosaurs - an unsteady aerodynamic approach. 47th AIAA Aerospace Sciences Meeting (Proceedings), pp. 1-37

55 Martin-Silverstone, E. (2017) Insights into mass estimation, pneumaticity, and anatomy of pterosaurs: implications for locomotion. University of Southampton, PhD Thesis.

Available at https://eprints.soton.ac.uk/416889/

56 Claessens, L.P.A.M. et al. (2009) Respiratory evolution facilitated the origin of pterosaur flight and aerial gigantism. PLoS One 4, e4497

57 Dumont, E.R. (2010) Bone density and the lightweight skeletons of birds. Proc. R. Soc. B Biol. Sci. 277, 2193-2198

58 Martin, E.G. and Palmer, C. (2014) Air space proportion in pterosaur limb bones using computed tomography and its implications for previous estimates of pneumaticity. PLoS One 9, e97159

59 Martin, E.G. and Palmer, C. (2014) A novel method of estimating pterosaur skeletal mass using computed tomography scans. J. Vertebr. Paleontol. 34, 1466-1469

60 Tobalske, B.W. et al. (2004) Take-off mechanics in hummingbirds (Trochilidae). J. Exp. Biol. 207, 1345-1352

61 Earls, K.D. (2000) Kinematics and mechanics of ground take-off in the starling Sturnis Sturnus vulgaris and the quail Coturnix coturnix. J. Exp. Biol. 203, 725-739

62 Schutt, W.A.J. et al. (1997) The dynamics of flight-initiating jumps in the common vampire bat Desmodus rotundus. J. Exp. Biol. 203, 725-739

63 Riskin, D.K. and Hermanson, J.W. (2005) Independent evolution of running in vampire bats. Nature 434, 292

64 Paskins, K.E. et al. (2007) Take-off and landing forces and the evolution of controlled gliding in northern flying squirrels Glaucomys sabrinus. J. Exp. Biol. 210, 1413-1423

65 Socha, J.J. et al. (2005) A 3-D kinematic analysis of gliding in a flying snake, Chrysopelea paradisi. J. Exp. Biol. 208, 1817-33

66 Witton, M.P. (2008) A new approach to determining pterosaur body mass and its implications for pterosaur flight. Zitteliana B28, 143-159

67 Tucker, V.A. (1993) Gliding birds: reduction of induced drag by wing tip slots between the primary feathers. J. Exp. Biol. 180, 285-310

68 Alexander, D. (2002) Nature's Flyers: Birds, Insects, and the Biomechanics of Flight, Hopkins University Press.

69 Gardiner, J.D. et al. (2011) An association between ear and tail morphologies of bats and their foraging style. Can. J. Zool. 89, 90-99

70 Bowers, A.H. et al. (2016) On Wings of the Minimum Induced Drag: Spanload Implications for Aircraft and Birds. NASA Tech. Publ. at <https://ntrs.nasa.gov/search.jsp?R=20160003578> 
71 Zheng, X. et al. (2013) Hind wings in Basal birds and the evolution of leg feathers. Science 339, 1309-12

72 Prum, R.O. and Brush, A.H. (2002) The Evolutionary Origin And Diversification Of Feathers. Q. Rev. Biol. 77, 261-295

73 Norell, M.A. and Xu, X. (2005) Feathered Dinosaurs. Annu. Rev. Earth Planet. Sci. 33, 277-299

74 Dial, K.P. (2003) Wing-Assisted Incline Running and the Evolution of Flight. Science 299, 402-404

75 Padian, K. and Chiappe, L.M. (1998) The origin and early evolution of birds. Biol. Rev. Camb. Philos. Soc. 73, S0006323197005100

76 Ward, T.A. et al. (2015) A Review of Biomimetic Air Vehicle Research: 1984-2014. Int. J. Micro Air Veh. 7, 375-394

77 Shahid, F. et al. (2019) Design of flying robots inspired by the evolution of avian flight. Proc. Inst. Mech. Eng. Part C J. Mech. Eng. Sci. DOI: 10.1177/0954406219861995

78 Zakaria, M.Y. et al. (2015) Design Optimization of Flapping Ornithopters: The Pterosaur Replica in Forward Flight. DOI: 10.2514/1.C033154

79 Roberts, B. et al. (2011) Flight dynamics of a pterosaur-inspired aircraft utilizing a variable-placement vertical tail. Bioinspir. Biomim. 6, 026010

80 Essner, R.L. (2002) Three-dimensional launch kinematics in leaping, parachuting and gliding squirrels. J. Exp. Biol. 205, 2469-2477

81 Stewart, M.M. (1985) Arboreal Habitat Use and Parachuting by a Subtropical Forest Frog. J. Herpetol. 19, 391-401

82 Russell, A.P. (1979) The origin of parachuting locomotion in gekkonid lizards (Reptilia: Gekkonidae). Zool. J. Linn. Soc. 65, 233-249

83 Demes, B. et al. They seem to glide. Are there aerodynamic effects in leaping prosimian primates? , Zeitschrift für Morphologie und Anthropologie. (1991), E. Schweizerbart'sche Verlagsbuchhandlung, 373-385

84 Xu, G.-H. et al. (2012) A new stem-neopterygian fish from the Middle Triassic of China shows the earliest over-water gliding strategy of the vertebrates. Proc. R. Soc. B Biol. Sci. 280, 20122261-20122261

85 Colbert, E.H. (1970) The Triassic gliding reptile Icarosaurus. Bull. Am. Museum Nat. Hist. $143,85-142$

86 Dyke, G.J. et al. (2006) Flight of Sharovipteryx mirabilis: the world's first delta-winged glider. J. Evol. Biol. 19, 1040-1043 


\section{Figure Captions:}

Figure 1: Examples of the three main wing morphologies in vertebrate flight. A) Schematic drawing of a bird, bat and pterosaur wing showing homologous bones and wing outlines. Image by Mark Witton, used with permission. B) Fossils of vertebrates capable of powered flight. L-R: the early bird Archaeopteryx (wingspan c. $60 \mathrm{~cm}$ ), the extinct bat Palaeochiropteryx (wingspan c. $30 \mathrm{~cm}$ ) and the small pterosaur Aerodactylus (wingspan c. $50 \mathrm{~cm}$ ). f, feathers; lw, left wing; m, membrane; rw, right wing; sk, skull.

Figure 2: The non-avian dinosaur $Y i$ (left, fossil photo credit Xu Xing, used with permission; right, life reconstruction by Emily Willoughby, used with permission). This animal has an enlarged wrist element (the styliform element) and spread fingers supporting a membranous wing, but also possesses feathers (c. $50 \mathrm{~cm}$ wingspan). Such a combination is rare and unknown elsewhere in nature aside from its close relative Ambopteryx and could be copied with a biomimetic aircraft. f, feathers; lw, left wing; m, membrane; rw, right wing; se, styliform element; sk, skull.

Figure I (inside Box 2): Examples of non-powered flying vertebrates from the fossil record. From L-R: the gliding reptile Xianglong (wingspan c. $9 \mathrm{~cm}$, image from Mick Ellison, used with permission), the Triassic flying fish Potanichthys (length c. $10 \mathrm{~cm}$, image from Xu Guang-Hui, used with permission), and the Jurassic gliding mammal Volaticotherium (wingspan c. $16 \mathrm{~cm}$, image from Meng Jin, used with permission). f, feathers; lh, left humerus; lw, left wing; m, membrane; r, rib; rh, right humerus; rw, right wing; sk, skull.

Figure II (inside Box 2): Examples and associated reconstructions of unique flying vertebrates from the fossil record. A) the bizarre delta-winged reptile Sharovipteryx (legspan c. $15 \mathrm{~cm}$ ). Fossil image (left) from Nicholas C. Fraser, used with permission. Life reconstruction (right) by Mark Witton, used with permission. B) the 'four-winged' non-avian dinosaur Microraptor 
(wingspan c. $70 \mathrm{~cm}$ ). Fossil image (left) from Xu Xing, used with permission. Life reconstruction (right) by David Krentz, used with permission. C) Life reconstruction of the giant pterosaur Quetzalcoatlus northropi (wingspan c. 11 m), by David Krentz, used with permission. f, feathers; hl, hindlimbs; lw, left wing; m, membrane; rw, right wing; sk, skull. 


\section{Glossary}

Actinofibrils: slender structural filaments found in the membranes of pterosaur wings.

Aeroelasticity: study of the interaction between aerodynamic forces and non-rigid structures.

Angle of sweep: the angle at which the wing is directed backwards from its root, rather than at right angles to the body.

Apneumatic: non-pneumatic (air-filled), specifically referring to bones that are not filled with air.

Aspect ratio: the length of the wing divided by the average chord, typically calculated as the square of the span divided by the total wing area. High aspect ratio wings are proportionally long and thin, low aspect ratio are short and broad.

Ballistic launch: undergoing a jumping or bouncing launch.

Biomimetic: using nature or the natural world as inspiration to solve human problems such as designs.

Camber: the cord-wise curvature of a wing. This primarily affects the effective angle of attack, such that a cambered wing has a higher coefficient of lift than an uncambered one (i.e. it produces more lift per unit of wing area at any given airspeed).

Compliance: in material sciences, the inverse of stiffness.

Drag: the component of a fluid force that is aligned parallel to the flow. For a flying animal, this will primarily be a measure of resistance to movement through the air.

Lift: the component of a fluid force that is aligned perpendicular to the flow. For a flying animal, this will provide most weight support and thrust.

Lift coefficient: a dimensionless coefficient used in aerodynamics to compare the complex aspects related to an airfoil's performance. It takes into account the density of the fluid, the velocity of travel, and the size (area) of the wing.

Non-avialan dinosaurs: the traditional definition of dinosaurs, meaning all dinosaurs that do not include the flying avian dinosaurs, birds.

Phylogenetics: the study of how species are related to each other and the evolutionary relationships within groups of organisms.

Pitch: the position or rotation of an object about the horizontal axis.

Pneumatic: air-filled, specifically related to bones that are filled with air rather than marrow.

Powered flight: the process in which an object moves through the air without contacting the surface (flight), by means of generating a propulsive thrust (powered) rather than by merely exploiting lift generating surfaces and air such as in gliding or soaring.

Rachis: the main shaft of a feather.

Roll: the position or rotation of an object about the longitudinal axis.

Subcutaneous: under the skin, rather than within muscles or organs. 
Tensile strength: the capacity of a structure to withstand loads that elongate or stretch, the opposite of compressive strength.

Vane asymmetry: the tendency for some feathers to have one side of the rachis have longer barbs than those of the other, making the feather asymmetrical.

Yaw: The position or rotation of an object about the vertical axis. 